\title{
Article \\ Differential Clearance of $A \beta$ Species from the Brain by Brain Lymphatic Endothelial Cells in Zebrafish
}

\author{
Yun-Mi Jeong ${ }^{1,2}$, Jae-Geun Lee ${ }^{1,3}$, Hyun-Ju Cho ${ }^{1}$, Wang Sik Lee ${ }^{4}$, Jinyoung Jeong ${ }^{4,5}$ and Jeong-Soo Lee ${ }^{1,2,3, *(1)}$ \\ 1 Disease Target Structure Research Center, Korea Research Institute of Bioscience and Biotechnology, \\ 125 Gwahak-ro, Yuseong-gu, Daejeon 34141, Korea; angdoym@kribb.re.kr (Y.-M.J.); \\ jglee89@kribb.re.kr (J.-G.L.); alleles@kribb.re.kr (H.-J.C.) \\ 2 Dementia DTC R\&D Convergence Program, Korea Institute of Science and Technology, Hwarang-ro 14-gil 5, \\ Seongbuk-gu, Seoul 02792, Korea \\ 3 Department of Functional Genomics, KRIBB School, University of Science and Technology, 217 Gajeong-ro, \\ Yuseong-gu, Daejeon 34113, Korea \\ 4 Environmental Disease Research Center, Korea Research Institute of Bioscience and Biotechnology, \\ 125 Gwahak-ro, Yuseong-gu, Daejeon 34141, Korea; wang3026@kribb.re.kr (W.S.L.); jyjeong@kribb.re.kr (J.J.) \\ 5 Department of Biotechnology, KRIBB School, University of Science and Technology, 217 Gajeong-ro, \\ Yuseong-gu, Daejeon 34113, Korea \\ * Correspondence: jeongsoo@kribb.re.kr; Tel.: +82-42-860-4643
}

check for

updates

Citation: Jeong, Y.-M.; Lee, J.-G.; Cho, H.-J.; Lee, W.S.; Jeong, J.; Lee, J.-S. Differential Clearance of A $\beta$ Species from the Brain by Brain Lymphatic Endothelial Cells in Zebrafish. Int. J. Mol. Sci. 2021, 22, 11883. https://doi.org/10.3390/ ijms222111883

Academic Editor:

Maria Laura Giuffrida

Received: 8 October 2021

Accepted: 29 October 2021

Published: 2 November 2021

Publisher's Note: MDPI stays neutral with regard to jurisdictional claims in published maps and institutional affiliations.

Copyright: (c) 2021 by the authors. Licensee MDPI, Basel, Switzerland. This article is an open access article distributed under the terms and conditions of the Creative Commons Attribution (CC BY) license (https:/ / creativecommons.org/licenses/by/ $4.0 /)$.

\begin{abstract}
The failure of amyloid beta $(\mathrm{A} \beta)$ clearance is a major cause of Alzheimer's disease, and the brain lymphatic systems play a crucial role in clearing toxic proteins. Recently, brain lymphatic endothelial cells (BLECs), a non-lumenized lymphatic cell in the vertebrate brain, was identified, but $\mathrm{A} \beta$ clearance via this novel cell is not fully understood. We established an in vivo zebrafish model using fluorescently labeled $A \beta 42$ to investigate the role of BLECs in $A \beta$ clearance. We discovered the efficient clearance of monomeric $A \beta 42$ (mA $\beta 42)$ compared to oligomeric $A \beta 42$ (oA $\beta 42)$, which was illustrated by the selective uptake of $\mathrm{mA} \beta 42$ by BLECs and peripheral transport. The genetic depletion, pharmacological inhibition via the blocking of the mannose receptor, or the laser ablation of BLECs resulted in the defective clearance of $\mathrm{mA} \beta 42$. The treatment with an $\mathrm{A} \beta$ disaggregating agent facilitated the internalization of $\mathrm{oA} \beta 42$ into BLECs and improved the peripheral transport. Our findings reveal a new role of BLECs in the differential clearance of $\mathrm{mA} \beta 42$ from the brain and provide a novel therapeutic strategy based on promoting $\mathrm{A} \beta$ clearance.
\end{abstract}

Keywords: Alzheimer's disease; amyloid beta; brain lymphatic endothelial cells; zebrafish model

\section{Introduction}

Alzheimer's disease (AD), the most prevalent form of dementia, is a devastating neurodegenerative disease characterized by cognitive function impairment and memory loss. The pathological characteristics of AD include the extracellular deposition of amyloid beta $(\mathrm{A} \beta)$ and neurofibrillary tangles from tau phosphorylation [1]. Although the steady level of $A \beta$ is balanced between production and clearance with the dynamic aggregation and disassembly of $A \beta$ under normal conditions, an imbalance of the $A \beta$ level via perturbed clearance is considered to be a major initiating factor of late onset AD [2,3]. Such an imbalance results in the accumulation of monomeric $A \beta(\mathrm{mA} \beta)$ peptides in the brain, which then generate oligomers, fibrils, and plaques of $A \beta$. Oligomeric $A \beta(o A \beta)$ is thought to be the most toxic form of $A \beta$ species responsible for $A D$ [4]. These accumulated $A \beta$ species are fundamental as biomarkers for an in vivo diagnosis of AD by measuring their levels in the cerebrospinal fluid (CSF) or performing an amyloid-positron emission tomography (PET) [5]. Thus, it is of great importance to elucidate how different forms of A $\beta$ are cleared under normal and pathological conditions to understand the pathogenesis of AD and to develop an effective therapeutic strategy for AD by reducing the excessive deposition of toxic $A \beta$ species. 
The clearance of $A \beta$ from the brain occurs via intricate clearance systems consisting of two major pathways: the blood circulatory clearance, which transports $A \beta$ into the periphery, and the degradation of $A \beta$ by proteases, such as neprilysin, or intracellular degradation by glial cells in the brain [6]. The blood circulatory clearance pathway includes the transport of wastes from the brain parenchyma across the blood-brain barrier (BBB), the bulk flow of interstitial fluid (ISF), and the absorption of CSF into the blood circulatory or lymphatic system [7]. The A $\beta$ cleared from the brain into the periphery are eventually degraded by the red blood cells and macrophages in the circulation or by peripheral organs, such as the liver and kidney [6]. Although earlier mouse studies suggested that the majority of extracellular $A \beta$ was cleared via the transportation across the BBB, recent functional studies on the glymphatic (glial + lymphatic) system in the perivascular network and meningeal lymphatic vessels in the dura mater of the brain showed more complicated clearance routes [7-11]. In particular, recent functional studies revealed that the meningeal lymphatic vessels played critical roles in the drainage of CSF wastes, including A $\beta$, suggesting a dysfunction of the meningeal lymphatic vessels resulting in a defective $A \beta$ clearance in the brain, which is a key aggravating factor in AD pathology $[12,13]$.

Unlike meningeal lymphatic vessels in the dura mater (the most outer layer of the meninges), the lymphatic vessels of leptomeninges, including the arachnoid and pia mater, were not studied. However, studies in zebrafish identified a distinct non-lumenized meningeal lymphatic cell population, called brain/mural lymphatic endothelial cells (BLECs/muLECs), fluorescent granule perithelial cells (FGPs), or Mato cells that express multiple lymphatic markers [14-16] (hereafter denoted as BLECs). Recently, these BLECs were also found in mouse and human leptomeninges, sharing morphological features and molecular markers [17]. BLECs are able to internalize macromolecules such as A $\beta 40$ from the brain or take up lipids with a close proximity to the vasculature, suggesting their involvement in the brain clearance system [14,16-18]. However, the exact role of BLECs in $\mathrm{AD}$ pathology and the mechanism by which BLECs clear different forms of $\mathrm{A} \beta$ species remain to be determined.

In the current study, we established an in vivo zebrafish larval model to investigate the function of BLECs in the clearance of $A \beta 42$, by taking advantage of the transparency of the zebrafish larval brain using cell type-specific fluorescent live reporter lines. Using this model, we performed in vivo, real-time analyses of the initial accumulation followed by the clearance of fluorescently labeled $A \beta 42$ depending on their aggregation status; that is, the $\mathrm{mA} \beta 42$ or $\mathrm{o} A \beta 42$ forms. We found that $\mathrm{mA} \beta 42$ was readily cleared from the brain by the absorption into BLECs, eventually accumulating in the peripheral pronephros for excretion, whereas oA $\beta 42$ remained mostly unchanged inside the brain. The BLEC depletion by ccbe1 (collagen and calcium binding EGF domains 1) gene knockdown or selective cell ablation using a laser, or the pharmacological inhibition of BLEC function using a mannose receptor agonist, exhibited a reduced pronephric accumulation of $\mathrm{mA} \beta 42$. These results support a specific role of BLECs in the clearance of $\mathrm{mA} \beta$. The treatment with an $A \beta$ disaggregating small-molecule EPPS [4-(2-hydroxyethyl)-1-piperazinepropanesulfonic acid] enhanced the BLEC localization and transport of disaggregated oA $\beta 42$ into the peripheral pronephros, corroborating the selectivity of $\mathrm{mA} \beta 42$ clearance by BLECs. Taken together, our analyses reveal a role of recently identified lymphatic cells and BLECs in selectively clearing $\mathrm{mA} \beta 42$ from the brain in vivo. This finding furthers our understanding of the clearance mechanisms of $A \beta$ in vivo and provides an in vivo platform and a strategy to discover and validate novel $\mathrm{AD}$ therapies based on modulating the functionality of BLECs for efficient $A \beta$ clearance.

\section{Results}

\subsection{Monomeric and Oligomeric A 422 Are Differentially Cleared from the Brain}

To investigate the role of the BLECs in A $\beta 42$ clearance in vivo, we first established a zebrafish larval model for monitoring $A \beta$ clearance by the cerebroventricular injection of a fluorescently labeled A $\beta 42$ into the zebrafish larval brain. We prepared two kinds 
of $A \beta$ peptides, $\mathrm{mA} \beta 42$ and $\mathrm{o} A \beta 42$, to compare the clearance efficiency using our model. The oligmeric form of the $A \beta$ peptide is thought to be the most toxic species and resistant to clearance $[4,19]$. The fluorescently labeled oA $\beta 42$ was prepared by incubating the fluorescently labeled $\mathrm{mA} \beta 42$ at $37^{\circ} \mathrm{C}$, according to the previously reported protocol [20]. Fluorescently labeled $\mathrm{A} \beta 42$ was shown to exhibit structures and is functionality comparable to unlabeled $A \beta 42$ under an aggregation condition [21]. We confirmed the respective structures by using atomic force microscopy (AFM) (Figure S1). The mA $\beta 42$ or oA $\beta 42$ peptides were introduced by a microinjection into the brain ventricle between the optic tectum and the hindbrain of zebrafish larvae at 3 days post-fertilization (dpf), and the clearance of the peptides from the brain was followed at 5 and $24 \mathrm{~h}$ post-injection (hpi) for a quantification based on the fluorescence area (Figure 1A). The fluorescence of injected $\mathrm{mA} \beta 42$ or oA $\beta 42$ was observed along the brain structures, such as the optic tectum and the hindbrain region (Figure $1 \mathrm{~B}-\mathrm{C}^{\prime}$ ). The $\mathrm{mA} \beta 42$ fluorescence decreased by more than $30 \%$ from 5 hpi to 24 hpi (Figure $\left.1 B, B^{\prime}, D, F\right)$. In contrast, the clearance rate of oA $\beta 42$ was significantly reduced compared to that of $\mathrm{mA} \beta 42(32.12 \pm 3.6 \% \mathrm{~mA} \beta 42$ injection vs. $16.90 \pm 4.6 \%$ oA $\beta 42$ injection, $p=0.0233$, two-tailed unpaired $t$-test, $n=7$ per group) (Figure $1 \mathrm{C}, \mathrm{C}^{\prime}, \mathrm{E}, \mathrm{F}$ ). Such differential clearance efficiency of $A \beta 42$, depending on the aggregation status (a rapid or slowed clearance of $\mathrm{mA} \beta 42$ or $\mathrm{oA} \beta 42$, respectively), was similar to the previous observation of the clearance of $\mathrm{mA} \beta 40$ or oA $\beta 40$ in the mouse brain [22].

To evaluate the cellular toxicity induced by different forms of $A \beta 42$ in the brain of zebrafish larvae, we analyzed the cell death after an A $\beta 42$ injection by acridine orange staining, which labeled the condensed chromatins [23]. The injection of oA $\beta 42$ induced massive cell death in the brain, especially in the hindbrain, whereas the injection of $\mathrm{mA} \beta 42$ did not (Figure S2). The fluorescence by fluor-labeled A $\beta 42$ was co-localized with the anti-pan- $\beta$-amyloid antibody (4G8), confirming that the fluorescence represented the actual $A \beta 42$ peptides (Figure S3A-D). Taken together, these results reveal the differential clearance of $A \beta$, depending on its aggregation status, using a successfully established acute zebrafish larval model that can visualize and monitor the clearance dynamics of $A \beta 42$ in the brain in vivo and in real time. This acute $A \beta 42$ injection zebrafish model can be utilized as a unique, experimental in vivo platform to investigate the brain clearance system regarding A $\beta 42$ removal in real time and under in vivo conditions.

\subsection{Cleared $m A \beta 42$ Accumulates in the Pronephros via Blood Flow}

We next investigated whether the cleared fluorescent $A \beta 42$ from the brain was transported into the periphery in our $A \beta$ clearance model. The kidney is considered to be one of the major peripheral organs for $A \beta$ clearance in both human and animal studies $[6,24]$. Recently, Tian and colleagues showed that the kidney removed $A \beta$ from the blood, and proposed the pathophysiological significance of the renal clearance of $A \beta$ in mammals [25]. We observed a similar clearance as a consequence of $A \beta$ in the zebrafish pronephros (Figure 2), a functional kidney counterpart in the larval stages consisting of the glomerulus and bilateral pronephric tubules fused with the vascular structure at the midline [26]. We observed the accumulation of $\mathrm{mA} \beta 42$ in the pronephric tubules at $4 \mathrm{hpi}$, suggesting that $\mathrm{mA} \beta 42$ introduced via injection was promptly cleared from the brain and transported into the pronephros, as a main periphery organ for clearance in our model (Figure 2A, $\mathrm{J}^{\prime}$ and Figure $\mathrm{S} 4 \mathrm{C}, \mathrm{D})$. In contrast, the fluorescence of oA $\beta 42$ in the pronephros was significantly reduced (Figure $2 \mathrm{~K}^{\prime}$ and Figure S4E,F), with a reduction greater than $80 \%$ (two-tailed unpaired $t$ test, $p=0.0002$ ), compared to that of $\mathrm{mA} \beta 42$ (Figure 2I). The accumulation of $\mathrm{mA} \beta 42$ and $\mathrm{oA} \beta 42$ in the pronephros shown by the fluorescence was also confirmed by an anti-pan- $\beta$-amyloid antibody (4G8) analysis (Figure S3E,F). 


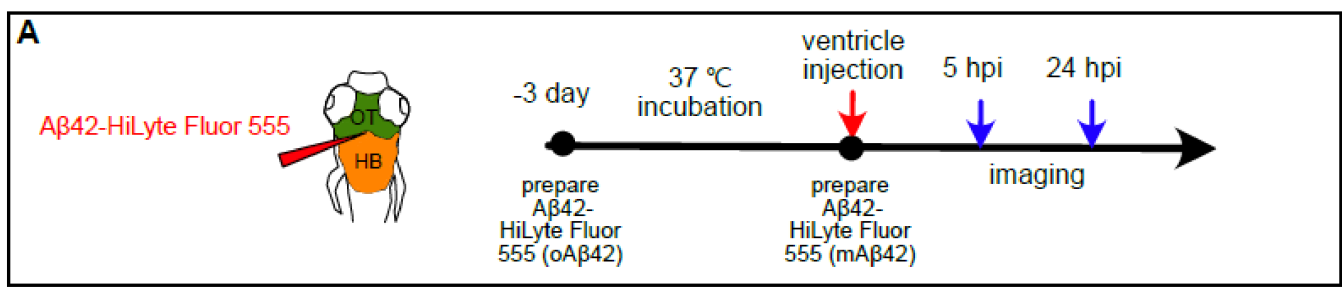

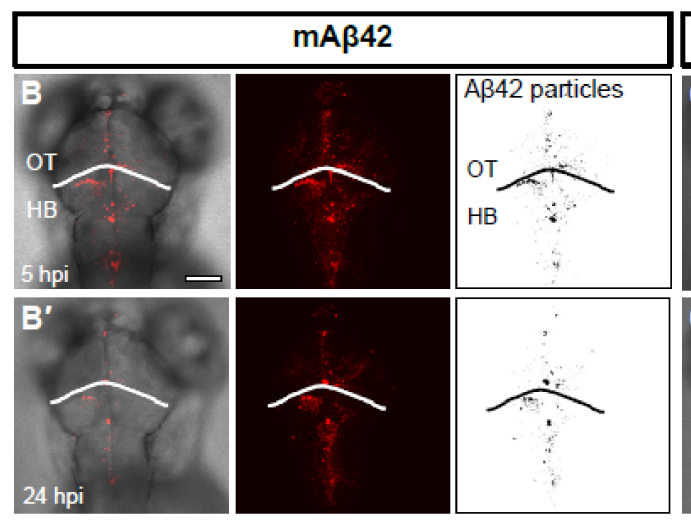

D

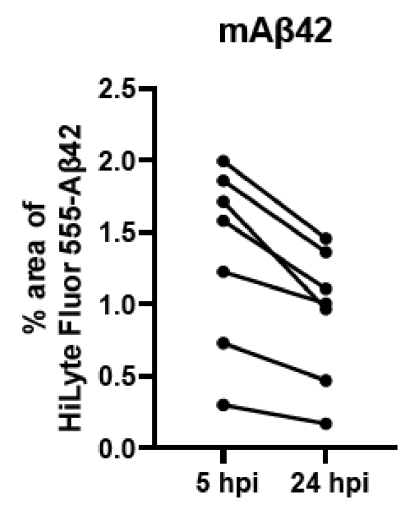

E

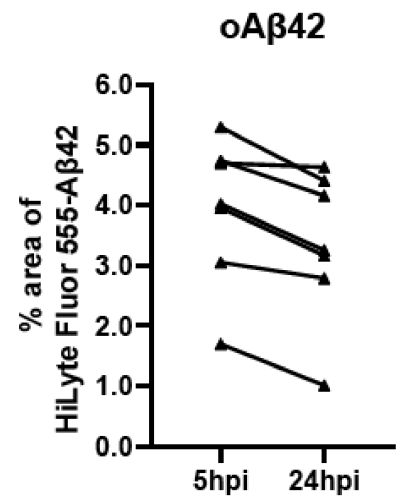

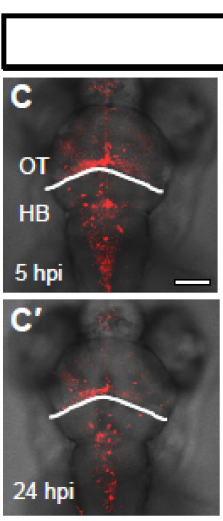

oA 342

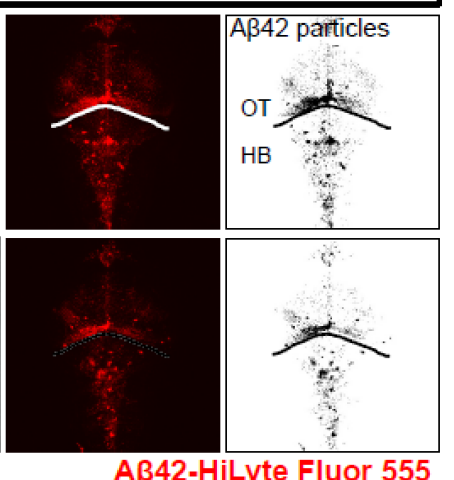

$\mathbf{F}$

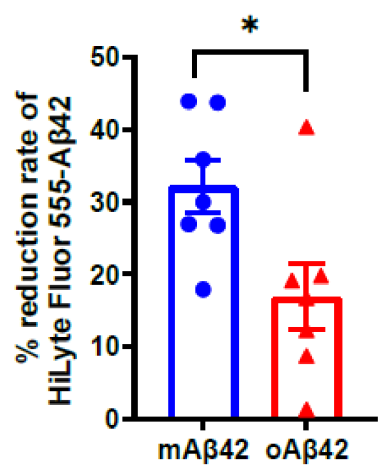

Figure 1. Monomeric A $\beta 42$ peptides are more efficiently cleared from the brain than oligomeric A $\beta 42$. (A) A schematic diagram of experimental setup. Fluorescently labeled A $\beta 42$ prepared at different time points were injected into the brain followed by in vivo imaging at $5 \mathrm{hpi}$ and $24 \mathrm{hpi}$. $\left(\mathbf{B}, \mathbf{C}^{\prime}\right)$ Distribution of injected, fluorescently labeled A $\beta 42$ (mA $\beta 42$ or oA $\beta 42)$ in the brains of $3 \mathrm{dpf}$ larvae at $5 \mathrm{hpi}(\mathbf{B}, \mathbf{C})$ and $24 \mathrm{hpi}\left(\mathbf{B}^{\prime}, \mathbf{C}^{\prime}\right)$ (left, overlays with brightfield; middle, HiLyte Fluor 555; right, thresholded images of $A \beta 42$ fluorescence). (D,E) Quantification of the area fraction (\%) occupied by A $\beta 42$ fluorescence within square unit $(512 \times 512$ pixels) at different time points. (F) Clearance rate of $\mathrm{mA} \beta 42$ and oA $\beta 42$ between 5 hpi and $24 \mathrm{hpi}$ by fluorescence quantification. Two-tailed unpaired $t$-test, $p=0.023$. Data are presented as mean $\pm \mathrm{SEM}$. $\mathrm{N}=7$ per group. Data are representative of at least three independent experiments. dpf, days post fertilization; hpi, hours post injection; HB, hindbrain; OT, optic tectum, Scale bars $=100 \mu \mathrm{m} .{ }^{*} p<0.05$.

To verify that the pronephric accumulation of $\mathrm{mA} \beta 42$ was mediated by blood flow, we dampened the heartbeat by using propranolol treatment and checked whether the pronephric accumulation of $\mathrm{mA} \beta 42$ was affected (Figure 2A,B). The treatment with propranolol, a non-selective $\beta$-adrenergic receptor blocker, resulted in a significant decrease in the heart rate (Figure 2E). The injection of $\mathrm{mA} \beta 42$ into the propranolol-treated larval brain resulted in a significant decrease $(\sim 43 \%$ reduction; two-tailed unpaired $t$ test, $p=0.0013 ; n=8$ per group) in the pronephric accumulation of $\mathrm{mA} \beta 42$ compared to the control (Figure $2 \mathrm{~A}, \mathrm{~B}, \mathrm{~F}$ ), suggesting that the pronephric accumulation of $\mathrm{mA} \beta 42$ in our model depended on blood flow. To rule out the potential unintended side effects of propranolol, we alternatively blocked the heartbeat using the morpholino against $t n n t 2 a$, an essential gene for heartbeat [27]. Upon tnnt2a knockdown, the pronephric accumulation 
of brain-injected $\mathrm{mA} \beta 42$ was also significantly decreased ( $\sim 49 \%$ reduction, two-tailed unpaired $t$ test, $p<0.0001 ; n=9$ per group) compared to the control (Figure 2C,D,G).

To further confirm that the introduced $\mathrm{mA} \beta 42$ in the brain may be transported to the pronephros via blood circulation in our model, we first injected $\mathrm{mA} \beta 42$ or oA $\beta 42$ into the ventricle of the brain at $3 \mathrm{dpf}$, followed by the injection of fluorescently labeled $10 \mathrm{kDa}$ dextran as a tracer molecule into the caudal vein of the same larvae, which could be visualized throughout the vasculature and taken up by the pronephric tubules [28] (Figure $2 \mathrm{H}$ ). We observed that both the brain ventricle-injected $\mathrm{mA} \beta 42$ and the peripheral vein-injected tracer were co-localized in the pronephric tubule (Figure 2J-J"', red and green colors, respectively). In contrast, oA $\beta 42$ injected larvae showed a low and weak accumulation even when the tracer was highly visible in the pronephros (Figure $2 \mathrm{~K}-\mathrm{K}^{\prime \prime \prime}$ ). The transverse sections at the level of the pronephric tubules of these larvae also showed an uptake of $10 \mathrm{kDa}$-dextran together with $\mathrm{mA} \beta 42$, but not with oA $\beta 42$ (Figure S4H,I). Taken together, these results implied a blood circulatory clearance system through which $\mathrm{mA} \beta 42$, but not $\mathrm{oA} \beta 42$, was transported from the brain into the peripheral tissue for degradation and excretion.

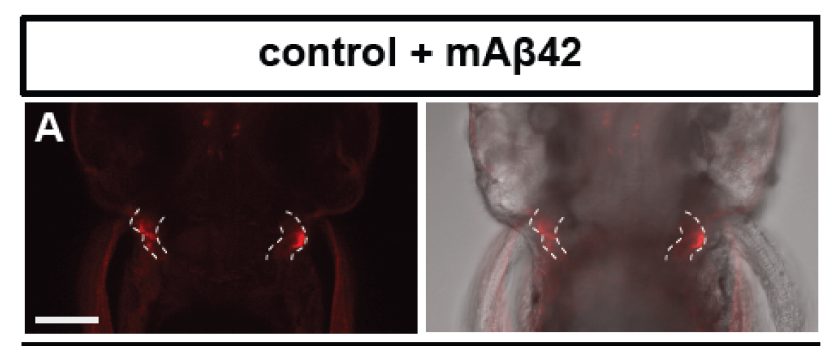

propranolol + mA $\beta 42$

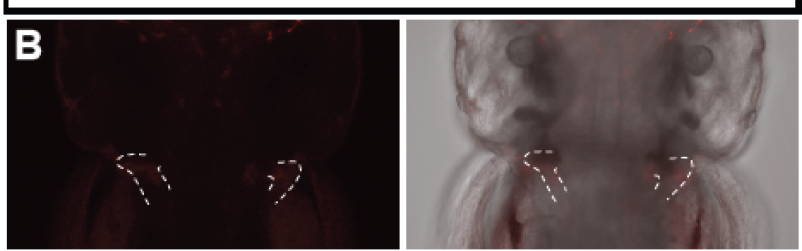

Aß42-HiLyte Fluor 647
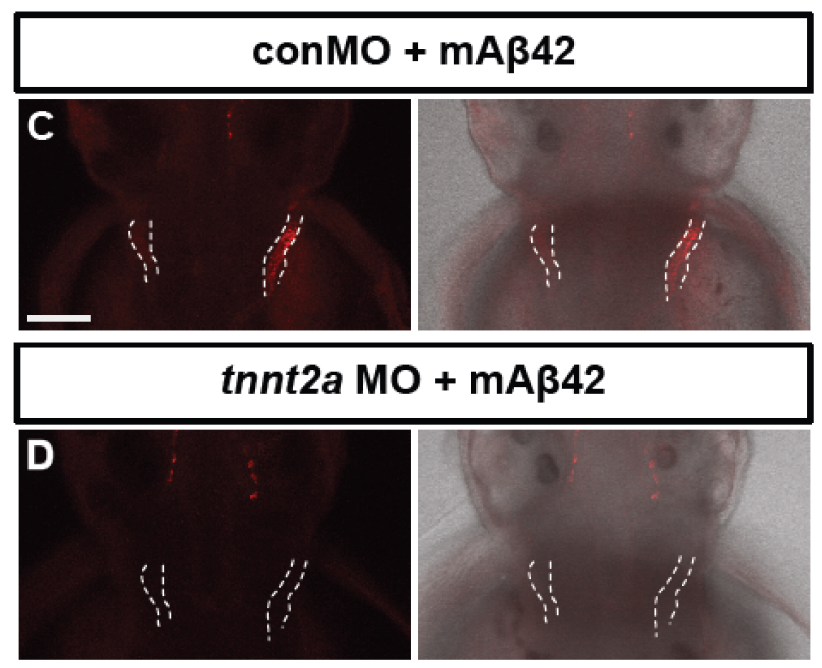

Aß42-HiLyte Fluor 647
E

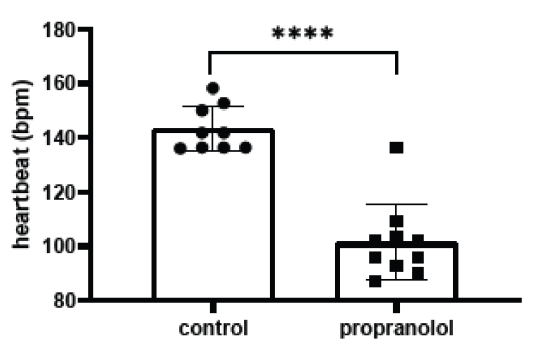

$\mathbf{F}$

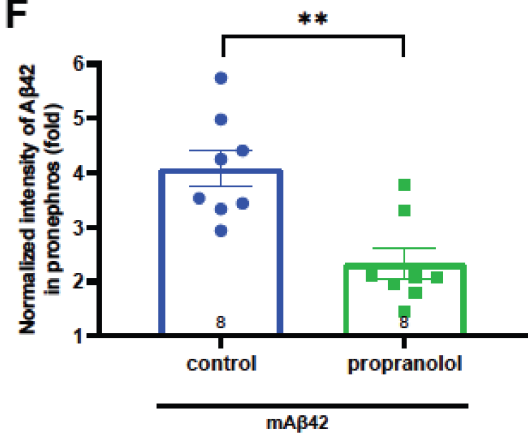

Figure 2. Cont.

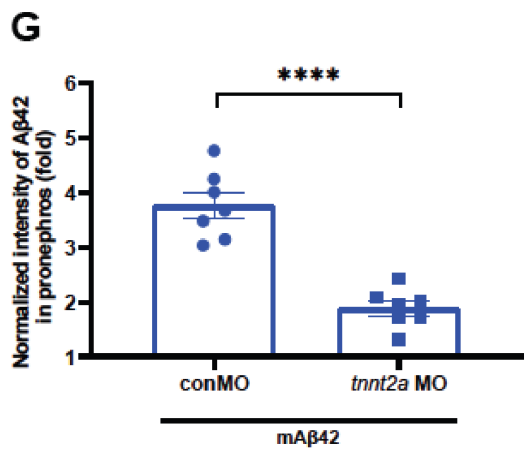




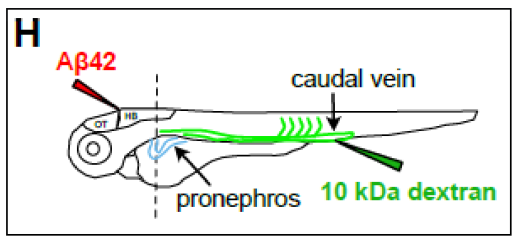

I

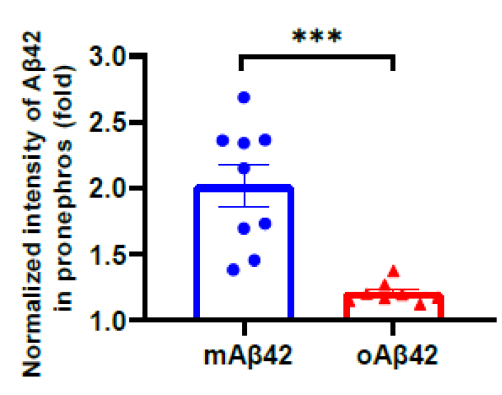

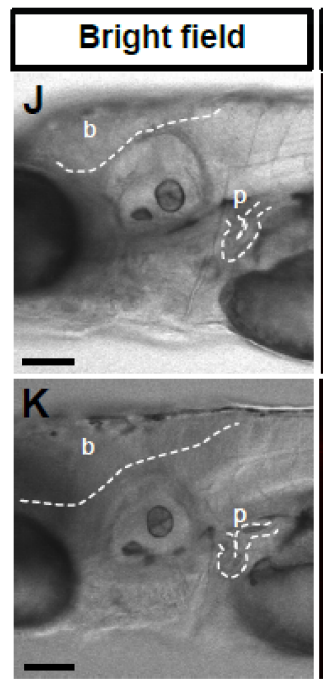
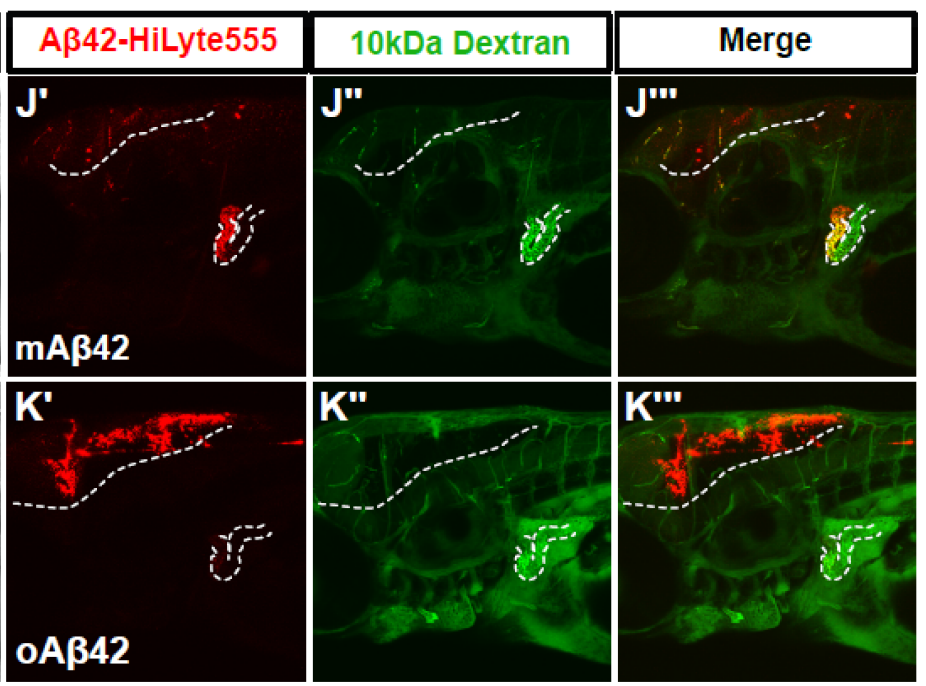

Figure 2. Cleared $\mathrm{mA} \beta 42$ accumulates in the pronephros via blood flow. (A,B) mA $\beta 42$-injected larvae after propranolol $(100 \mu \mathrm{M})$ treatment. The $\mathrm{mA} \beta 42$ intensity in the pronephros of propranolol-treated larvae (white dotted lines) decreased (B) compared to control (A). (C,D) mA 342 -injected larvae after control morphants (C) and $200 \mu \mathrm{M}$ tnnt $2 a$ morphants (D). (E) Quantification of heartbeats upon propranolol treatment. $n=9$ for control group, $n=10$ for propranolol. (F) Quantification of the mA $\beta 42$ intensity in the pronephros after propranolol treatment. $n=8$ per group. (G) Quantification of the mA $\beta 42$ intensity in the pronephros of control and tnnt2a morphants. Statistical significance was determined by two tailed unpaired $t$-test. Data are presented as mean \pm SEM. $n=9$ per group. Data are representative of at least three independent experiments. (H) A schematic diagram of experimental setting of $\mathrm{A} \beta$ and tracer injection. $\mathrm{mA} \beta 42$ or oA $\beta 42$ (HiLyte) was injected into ventricle and $10 \mathrm{kDa}$ Dextran was injected into caudal vein. (I) Quantification of the A $\beta 42$ fluorescence intensity in the pronephros normalized by background fluorescence. $n=9$ for $\mathrm{mA} \beta 42, n=8$ for oA $\beta 42$. Data are representative of at least three independent experiments. ( $\left.\mathbf{J}-\mathbf{K}^{\prime \prime \prime}\right)$ Confocal fluorescence images showing the brain and pronephros of zebrafish with lateral view after $\mathrm{mA} \beta 42(\mathrm{~J})$ or oA $\beta 42(\mathbf{K})$ injection at $3 \mathrm{dpf}$. Red fluorescence indicates A $\beta 42-H i L y t e$ Fluor and green fluorescence show $10 \mathrm{kDa}$ dextran tracer injected into caudal vein. $\left(\mathrm{J}^{\prime}\right)$ Ventricle-injected $\mathrm{mA} \beta 42$ was seen in the pronephros region (white dotted lines and depicted as p). $\left(\mathbf{K}^{\prime}\right)$ Ventricle-injected oA $\beta 42$ was seen only in the brain region (b), but not detected in the pronephros. Caudal vein-injected dextran accumulated in the pronephros of both $\mathrm{mA} \beta 42$ and oA $\beta 42$-injected larvae $\left(\mathbf{J}^{\prime \prime}, \mathbf{K}^{\prime \prime}\right)$. $\left(\mathbf{J}^{\prime \prime \prime}, \mathbf{K}^{\prime \prime \prime}\right)$ show merged images. b, brain; MO, morpholino; p, pronephros; Scale bars $=100 \mu \mathrm{m} .{ }^{* *} p<0.001 ;{ }^{* * *} p<0.0005 ;{ }^{* * * *} p<0.0001$.

\subsection{Monomeric A $\beta 42$ Is Taken up by Brain Lymphatic Endothelial Cells}

Recently identified brain lymphatic endothelial cells (BLECs) may be implicated in the clearance of brain waste due to their anatomical proximity to the cerebrovasculature and their capability to internalize macromolecules from the brain [16]. However, the role of BLECs in amyloid pathology and the clearance of toxic $A \beta$ is not fully defined. In order to investigate the role of BLECs in A $\beta$ clearance, we performed the cerebroventricular injection of $\mathrm{mA} \beta 42$ or oA $\beta 42$ into transgenic lines, $\mathrm{Tg}$ (prox1a:KalTA4, UAS:TagRFP) and $T g(m r c 1 a: m C h e r r y)$, which expressed red fluorescent proteins in the lymphatic system that visualized 5 10 BLECs in the loop structure of the optic tectum at $3 \mathrm{dpf}[29,30]$ (Figure 3A,E-H). Upon mA $\beta 42$ injection, the A $\beta 42$ fluorescence (HiLyte Fluor 488 or 647) in the optic tectum was distinctly co-localized with prox1a- or mrc1a-positive cells in the BLEC loop (Figure 3B,E: the co-localization frequency of $\mathrm{mA} \beta 42$ in prox $1 a+$ BLECs $=91.80 \%$, $n=9)$. In particular, the robust uptake of $\mathrm{mA} \beta 42$ into the endocytic vesicles in BLECs was observed with high-resolution confocal imaging (Figure 3E, yellow arrows in Figure $3 \mathrm{E}^{\prime}$ ). In contrast, the co-localization of oA $\beta 42$ in BLECs was quite scarce following oA $\beta 42$ injection (Figure 3B,F: the co-localization frequency of oA $\beta 42$ in prox $1 a+$ BLECs, $12.04 \%$ ), and the endocytic vesicles in BLECs were barely positive with oA $\beta 42$ fluorescence (Figure $3 \mathrm{~F}$, white arrows in Figure $3 \mathrm{~F}^{\prime}$ ). To validate that the injected $\mathrm{mA} \beta 42$ was internalized into endocytic vesicles, we used pHrodo Green dextran (pHrodoGreen), which emitted a $\mathrm{pH}$-sensitive 
fluorescence upon its internalization in the acidic environment and was used to reveal the intracellular uptake in BLECs $[16,18]$. After $\mathrm{mA} \beta 42$ or oA $\beta 42$ injection, following pHrodo injection (Figure S5A), we observed the co-localization of $\mathrm{mA} \beta 42$ labeled with HiLyte Fluor 647 (mA $\beta 42-H i L y t e$ Fluor 647) and pHrodo in BLECs (Figure S5B), while oA $\beta 42$ was undetected in BLECs (Figure S5C), indicating that the $\mathrm{mA} \beta 42$ was actively internalized into the endocytic compartment of BLECs.

To further confirm that this differential $A \beta$ internalization, according to its aggregation status, occurs in BLECs but not in blood vessels in the brain, we examined the co-localization of fluorescent $\mathrm{A} \beta$ using the double transgenic line $\mathrm{Tg}$ (mrc1a:mCherry); $T g(k d r l: E G F P)$ to visualize BLECs and endothelial cells simultaneously. The majority of $\mathrm{mA} \beta 42$-HiLyte Fluor 647 that co-localized with mrc1a-positive BLECs in the optic tectum were neighbored by, but not overlapped with, $k d r l$-positive endothelial cells (magenta with yellow arrowheads in Figure 3G and Figure S6C). In contrast, oA $\beta 42$ was not overlapped with either mrc1a:mCherry-positive BLECs or the $k d r l: E G F P$-positive endothelial cells (Figure 3F,H and Figure S6B,D). Similar to the optic tectum region, $\mathrm{mA} \beta 42$ in the hindbrain was also detectable adjacent to the primordial hindbrain channels of $T g(k d r l: E G F P)$ (arrows in Figure S6E), whereas oA $\beta 42$ was seen only in the brain region devoid of the vasculature (Figure S6B,F). To determine whether the $\mathrm{mA} \beta 42$ was located in BLECs nearby vasculatures, we quantified the number of A $\beta$-positive BLECs colocalized with mrc1apositive BLECs within $10 \mu \mathrm{m}$ of the paired mesencephalic vein $(\mathrm{MsV})$, located in the dorsal midline of the brain (Figure 3D,G,H). The majority of $\mathrm{mA} \beta 42$ fluorescence nearby the MsV coincided with mrc1a-positive cells, whereas oA $\beta 42$ hardly overlapped with them (Figure 3D: ordinary one-way ANOVA with Tukey's test, $p<0.0001 ; n=10$ for $\mathrm{mA} \beta 42$ and $n=8$ for oA $\beta 42$ ). These suggest that the vasculature-associated BLECs participate in the selective internalization of $\mathrm{mA} \beta 42$ but not of oA $\beta 42$.

Since $A \beta$ oligomers are known to have toxicity with various mechanisms [31], the failure of oA $\beta 42$ internalization into BLECs may have occurred due to the toxic effect of oA $\beta 42$ damaging BLECs. To exclude such a possibility, we counted the number of BLECs in the optic tectum of the $T g(m r c 1 a: m C h e r r y)$ after $\mathrm{mA} \beta 42$ or oA $\beta 42$ injection. The number, as well as the gross shape, of BLECs in the optic tectum was comparable in both conditions (Figure 3C: compare Figure $3 \mathrm{E}, \mathrm{F}$ ), suggesting that the oA $\beta 42$ did not impair the anatomy and survival of BLECs. Thus, the decline in the internalization of oA $\beta 42$ into BLECs is likely due to the properties of $\mathrm{oA} \beta 42$, such as the size or structures of oligomers preventing its internalization into BLECs and their removal by the brain clearance system once $A \beta s$ are aggregated, which may explain $A \beta$ oligomer-specific accumulation and toxicity in AD pathogenesis.

A

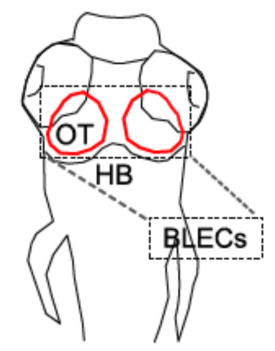

B

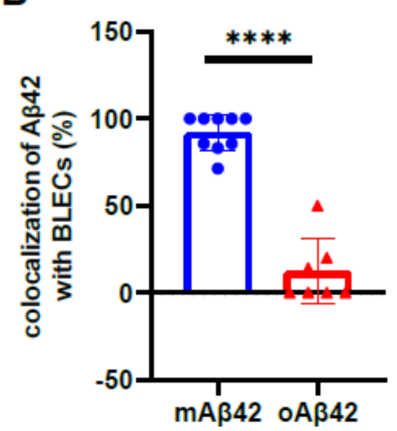

C

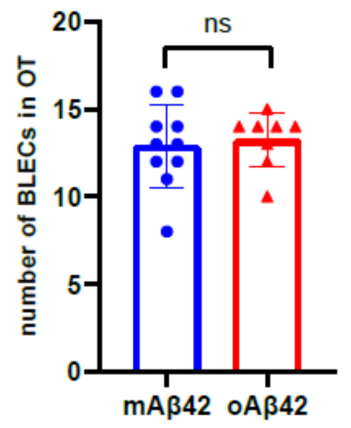

D

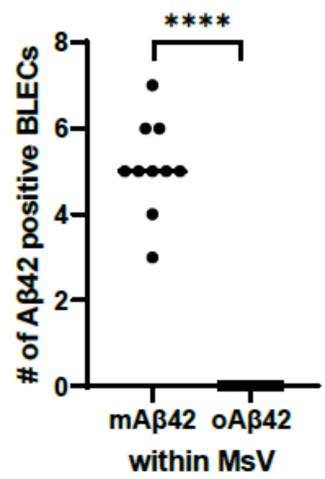

Figure 3. Cont. 

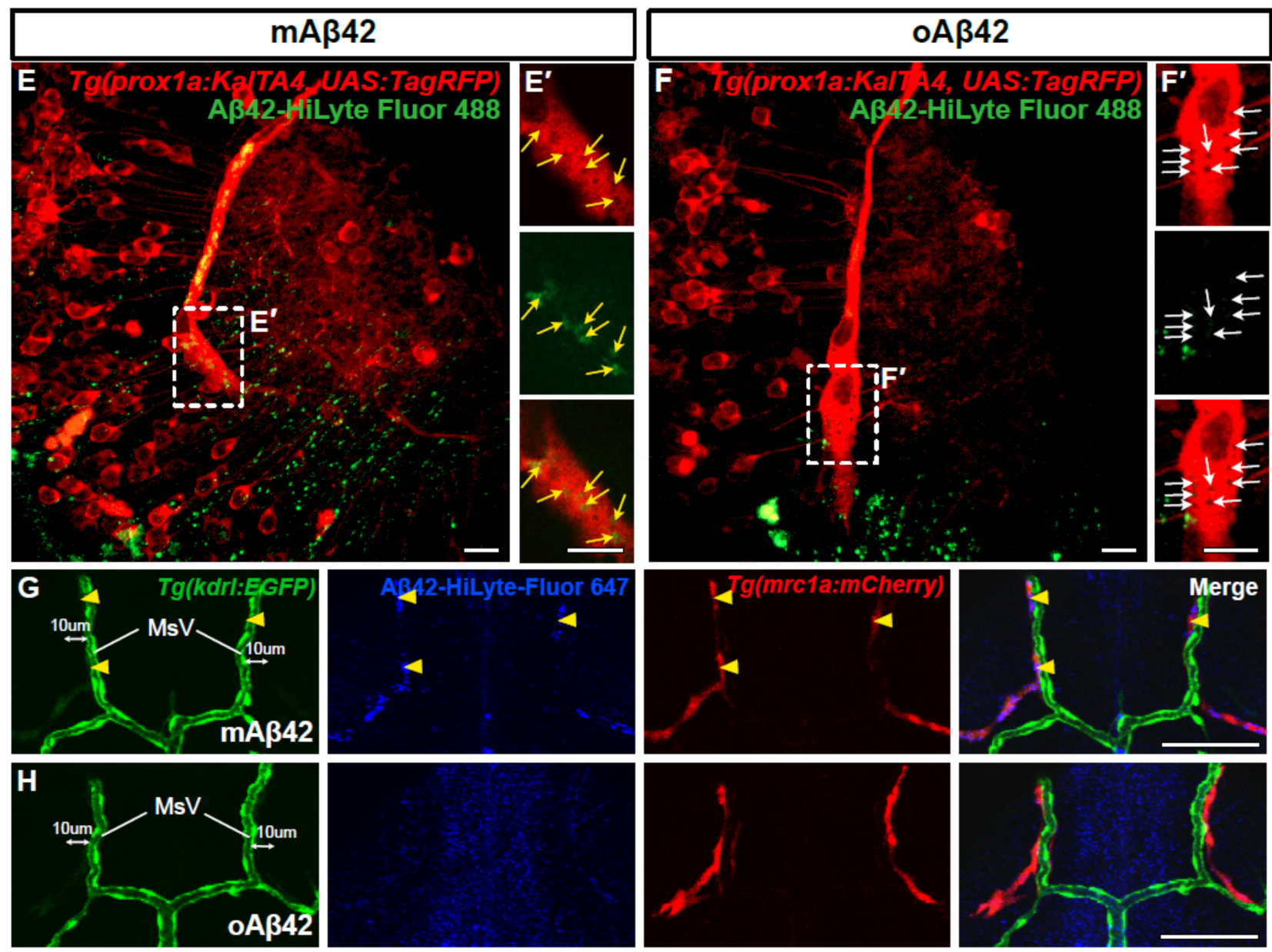

Figure 3. Brain lymphatic endothelial cells take up monomeric A $\beta 42$, but not oligomeric A $\beta 42$. (A) A schematic diagram of the larval brain with the dorsal view. Red lines in the dotted box depict the loop structure of the brain lymphatic endothelial cells (BLECs) in the optic tectum. (B) Quantification of the co-localization of A $\beta 42$ with BLECs. Data are presented as mean \pm SEM. $n=9$ for $\mathrm{mA} \beta 42$ and $n=7$ for oA $\beta 42$. Statistical significance was determined by two-tailed unpaired $t$-test. (C) Quantification of the numbers of $m r c 1 a+$ BLECs in the optic tectum after $\mathrm{mA} \beta 42$ or oA $\beta 42$ injection in the $\mathrm{Tg}$ (mrc1a:mCherry). Data are presented as mean \pm SEM. $n=9$ per group. (D) Quantification of the number of $A \beta 42$ positive BLECs nearby (within $10 \mu \mathrm{m}$ ) mesencephalic vein $(\mathrm{MsV})$ region showing $m r c 1 a+$ positivity. Statistical significance was determined by ordinary one-way ANOVA with Tukey's test. $n=10$ for $\mathrm{mA} \beta 42$ and $n=8$ for oA $\beta 42$. (E,F) Confocal projections of prox1a:RFP+ BLECs and A $\beta 42-$ HiLyte Fluor 488. $\left(\mathbf{E}^{\prime}, \mathbf{F}^{\prime}\right)$ High magnification of dotted boxes in $(\mathbf{E}, \mathbf{F})$ showing endocytic vesicles of BLECs. $\mathrm{mA} \beta 42$-injected BLECs showed robust uptake of $\mathrm{mA} \beta 42$ into endocytic vesicles $\left(\left(\mathbf{E}^{\prime}\right)\right.$, yellow arrows) whereas oA $\beta 42$-injected did weak uptake $\left(\left(\mathbf{F}^{\prime}\right)\right.$, white arrows). Scale bars in $\left(\mathbf{E}-\mathbf{F}^{\prime}\right)=10 \mu \mathrm{m}$. $(\mathbf{G}, \mathbf{H})$ Confocal fluorescence images of the brain optic tectum region with double transgenic $\operatorname{Tg}(k d r l: E G F P) ; \operatorname{Tg}(m r c 1 a: m C h e r r y)$ larvae after $\mathrm{A} \beta 42$ injection (HiLyte Fluor 647-A $\beta 42$ ) at 3 dpf. mA $\beta 42$ fluorescence detected in the neighboring (within $10 \mu \mathrm{m}$ ) $k d r l: E G F P+$ cerebrovasculature was mostly co-localized with mrc1a:mCherry+ BLECs (yellow arrowheads) (G), whereas $\mathrm{oA} \beta 42(\mathbf{H})$ fluorescence neighboring $k d r l: E G F P+$ cerebro-vasculatures was not. HB, hindbrain; OT, optic tectum; MsV, mesencephalic vein; Scale bars in $(\mathbf{G}, \mathbf{H})=50 \mu \mathrm{m}$. ns, not significant; ${ }^{* * * *} p<0.0001$.

The clearance of $\mathrm{mA} \beta 42$ in the BLECs from the brain was further confirmed by observing the fade-out of mA $\beta 42$ localized in mrc1a:mCherry-positive BLECs using the double transgenic line $T g(m r c 1 a: m C h e r r y) ; T g(k d r l: E G F P)$ in real time (Supplementary Video S1, Figure S7). Taken together, these data indicate that BLECs in the brain have a preference to internalize $\mathrm{mA} \beta 42$ over oA $\beta 42$ and participate in clearing the $\mathrm{mA} \beta 42$ from the brain. 


\subsection{BLEC Depletion Reduces the Peripheral Transport of $m A \beta 42$ to the Pronephros}

Although BLECs are known to internalize a variety of macromolecules, whether BLECs directly participate in the clearance and drainage of different forms of $A \beta 42$ in the brain has not been functionally validated. To test whether BLECs are necessary for the clearance of A $\beta 42$ in our zebrafish model, we depleted BLECs by knocking down the ccbe1 gene, encoding a component essential for lymphangiogenesis by processing Vegfc, using a morpholino against ccbe1 [32]. We confirmed the complete elimination of BLECs in the $c c b e 1$ morphants with vasculatures grossly intact by using a double transgenic line Tg(prox1a:KalTA4, UAS:TagRFP); Tg(fli1a:EGFP) (Figure 4B,C). Upon the cerebroventricular injection of $\mathrm{mA} \beta 42$ or oA $\beta 42$ in the control and ccbe1 morphants (Figure $4 \mathrm{D}-\mathrm{G}$ ), the depletion of BLECs by ccbe1 knockdown resulted in a significant reduction in $\mathrm{mA} \beta 42$ accumulation in the pronephros compared to the control based on the normalized intensity of $\mathrm{A} \beta 42$ fluorescence in the pronephros $(37.9 \pm 3.6 \%$ reduction, $p=0.0026$, ordinary oneway ANOVA with Tukey's test, $n=11$ for con MO, $n=10$ for $c c b e 1 \mathrm{MO}$; Figure $\left.4 \mathrm{D}^{\prime}, \mathrm{F}^{\prime}, \mathrm{H}\right)$. These results suggest that BLECs are required for clearing $\mathrm{mA} \beta 42$ in the brain through the blood circulatory clearance mechanism. Consistent with the observation that oA $\beta 42$ was localized away from BLECs (Figure 3), the accumulation of oA $\beta 42$ was almost unchanged irrespective of the presence of BLECs (Figure $4 \mathrm{E}^{\prime}, \mathrm{G}^{\prime}, \mathrm{H}$ ). The reduced accumulation of $\mathrm{mA} \beta 42$ in the pronephros upon the depletion of BLECs was also confirmed by comparing A $\beta 42$ fluorescence intensities of the pronephros relative to those of the hindbrain $(\sim 35 \%$ reduction, $p<0.0001$, ordinary one-way ANOVA with Tukey's test, $n=11$ for con MO, $n=10$ for $c c b e 1 \mathrm{MO}$; Figure $4 \mathrm{D}, \mathrm{F}, \mathrm{I})$. The defective pronephric delivery of $\mathrm{mA} \beta 42$ by the blood circulatory clearance upon BLEC depletion suggests that BLECs participate in clearing $\mathrm{mA} \beta 42$ from the brain through the blood circulatory routes. On the contrary, the clearance of oA $\beta 42$ was not affected in the ccbe1 morphants, which was consistent with the previous co-localization data (Figure 4E,G-I).

A
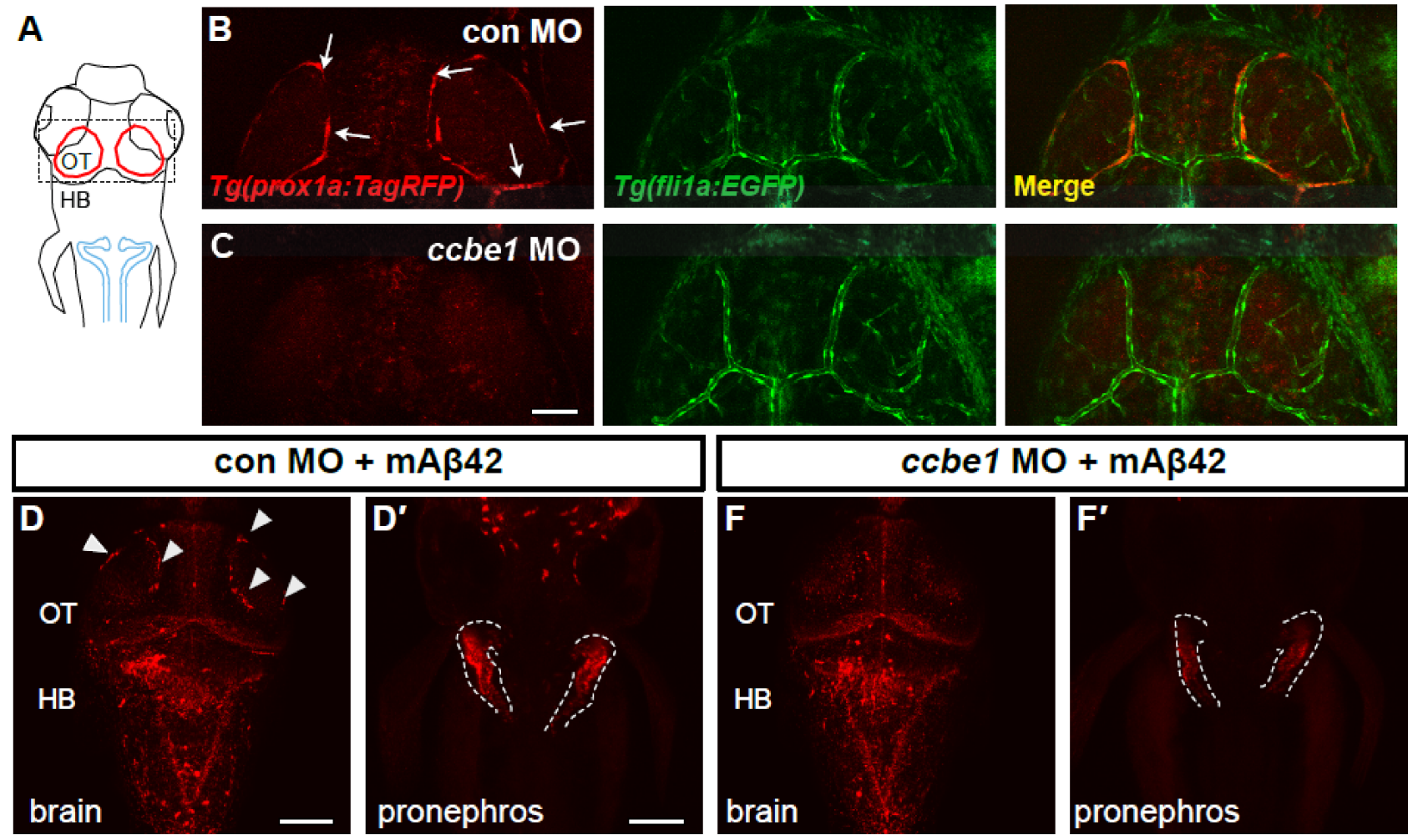

Figure 4. Cont. 

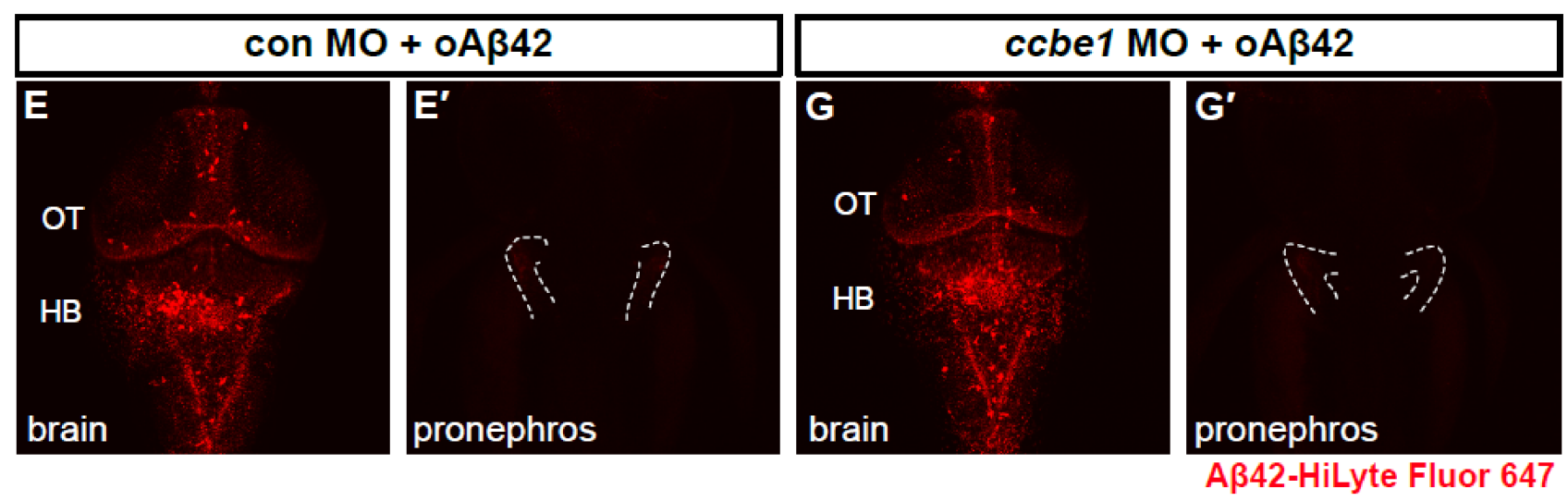

H Aß42 intensity in the pronephros

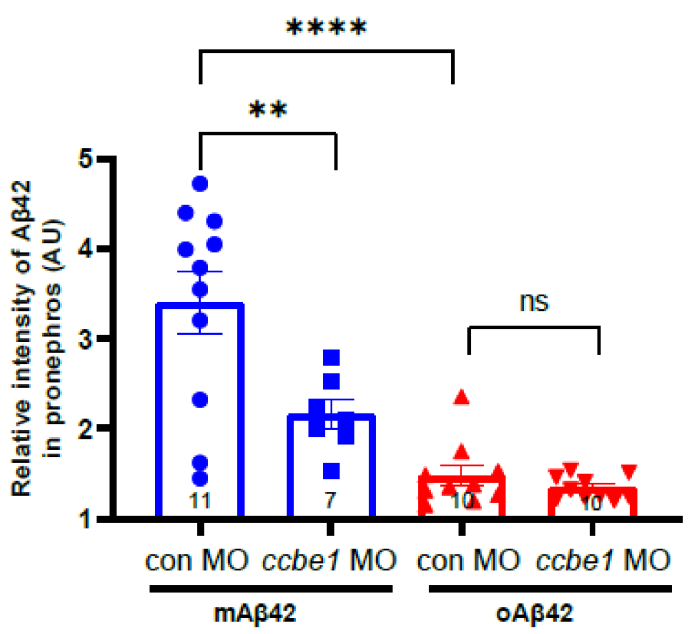

I

pronephros / hindbrain

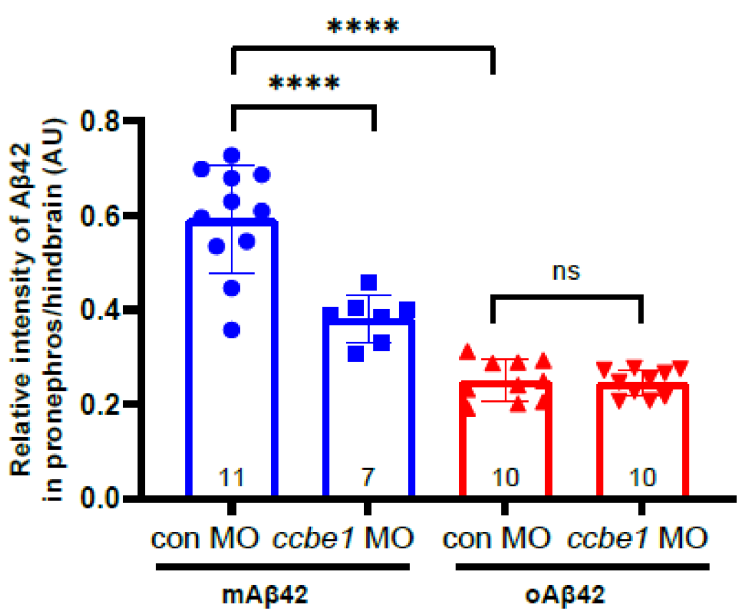

Figure 4. BLECs depletion decreases peripheral transport of $\mathrm{mA} \beta 42$ to the pronephros. (A) A schematic diagram of zebrafish $3 \mathrm{dpf}$ larvae with dorsal view. Dotted box depicts the loop structure of BLECs in the optic tectum. Blue lines depict the pronephros. (B,C) Confocal fluorescence images of the brain optic tectum region with Tg(prox1a:TagRFP); Tg(fli1a:EGFP) that labels BLECs and brain vasculatures simultaneously. Control morphant (B) and ccbe1 morphant (C) at $3 \mathrm{dpf}$ with BLECs depleted in the brain with intact vasculatures. Scale bar in $C=50 \mu \mathrm{m}$. (D-G) Dorsal view of the larval brains of control (D,E) and ccbe1 morphants $(\mathbf{F}, \mathrm{G}) 4 \mathrm{~h}$ after $\mathrm{A} \beta 42$ injection at $3 \mathrm{dpf}$. Red fluorescence represents A $\beta 42$-HiLyte Fluor 647 . mA $\beta 42$ is seen in BLECs (arrowheads) in the control morphants (D) but not in the ccbe1 morphants $(\mathbf{F}) .\left(\mathbf{D}^{\prime}, \mathbf{E}^{\prime}, \mathbf{F}^{\prime}, \mathbf{G}^{\prime}\right)$ Confocal images of zebrafish pronephros (dotted lines) after $\mathrm{A} \beta 42$ (the same fish with brain images). The robust pronephric accumulation of $\mathrm{A} \beta 42$ was detectable in $\mathrm{mA} \beta 42$-injected control $\left(\mathbf{D}^{\prime}\right)$, but the reduced pronephric delivery of $\mathrm{mA} \beta 42$ was observed in $c c b e 1$ morphants $\left(\mathrm{F}^{\prime}\right)$ compared to control. oA $\beta 42$ injection into both control and ccbe1 morphants show almost no pronephric accumulation of $A \beta 42\left(\mathbf{E}^{\prime}, \mathbf{G}^{\prime}\right)$. Scale bars $=100 \mu \mathrm{m}$. $(\mathbf{H})$ Quantification of $A \beta 42$ intensity in the pronephros, normalized by the intensity of non-fluorescent background. (I) Quantification of the relative intensity ratio between the pronephros and hindbrain. Statistical significance was determined by ordinary one-way ANOVA with Tukey's test. HB, hindbrain; MO, morpholino; OT, optic tectum; $n$, independent biological samples or animals. Numbers within bar bottom graphs represent $n .^{* *}, p<0.01 ;{ }^{* * *}, p<0.0001 ;$ ns, not significant. 
Since ccbe1 knockdown may cause the unintended additional depletion of facial and trunk lymphatics, we performed a more fine-tuned cell ablation strategy specific for BLECs using direct laser ablation. The laser ablation protocol, using a laser-scanning confocal microscope equipped with the common $405 \mathrm{~nm}$ laser [33], resulted in the specific ablation of BLECs (Figure 5A-C) without any obvious defect in the cerebrovasculature revealed by $T g(k d r l: E G F P)$ (Figure 5B,C). The laser irradiation resulted in a significant reduction in the number of mrc1a:mCherry-positive cells in the brain region ( $79.74 \%$ reduction in $m r c 1 a+$ BLECs compared to the number before ablation) (Figure 5G). To confirm the function of BLECs in $A \beta$ clearance after specific ablation, $\mathrm{mA} \beta 42$ was injected into the ventricle after BLEC ablation and the pronephric accumulation of A $\beta 42$ was measured (Figure 5D-F). The BLEC ablation using the laser resulted in a significant reduction in $\mathrm{mA} \beta 42$ localized in the BLECs (Figure 5D, $\mathrm{D}^{\prime \prime \prime}$ ) compared to the control (Figure 5E, $\mathrm{E}^{\prime}$ ). Importantly, the $\mathrm{mA} \beta 42$ drainage to the pronephros was significantly reduced $(\sim 21 \%$ reduction, $p=0.0092$, two-tailed unpaired $t$ test, $n=15$ for control, $n=8$ for ablation; the combined results for three experiments with the identical experimental settings) (Figure 5F), confirming a specific requirement of BLECs in the $\mathrm{mA} \beta 42$ clearance from the brain.

\subsection{Mannan Administration Reduces $m A \beta 42$ Internalization by BLECs and Peripheral Transport}

BLECs take up macromolecules from the CSF in a Mannose receptor 1a (Mrcla)dependent manner; this process is abrogated by the treatment of mannan, a known competitive agonist of Mrcla [16]. We reasoned that the internalization of $\mathrm{mA} \beta 42$ into BLECs may also be Mrcla-dependent, and thus affected by mannan treatment. We tested the BLEC function in clearing $\mathrm{mA} \beta 42$ pharmacologically with a minimal effect on undesirable vascular function at a systemic level. We introduced mannan and pHrodo Green into the brain ventricle immediately followed by an A $\beta 42$ injection within 5-10 min and examined whether the mA $\beta 42$ uptake into BLECs and its clearance were affected. Mannan administration showed grossly similar localization patterns of $\mathrm{mA} \beta 42$ in BLECs to PBS administration (Figure 6B,C). However, the high-resolution confocal imaging revealed that the $\mathrm{mA} \beta 42$ fluorescence observed in BLECs upon mannan treatment accumulated mostly in the membrane surfaces and did not co-localize with the pHrodo marker suggesting the failure of the internalization of $\mathrm{mA} \beta 42$ into the cytoplasmic components of BLECs upon mannan treatment (Figure $6 \mathrm{C}$ ). Consistent with this observation, mannan treatment also significantly reduced the pronephric accumulation of $\mathrm{mA} \beta 42$ compared to PBS treatment $(\sim 15 \%$ reduction, $p=0.0092$, Figure $6 \mathrm{D}-\mathrm{F})$, suggesting that BLECs were implicated in $\mathrm{mA} \beta 42$ clearance, partly via the Mrcla-dependent internalization of $\mathrm{mA} \beta 42$. Taken together, the depletion of BLECs by a genetic knockdown and laser ablation, as well as the inhibition of BLECs, functions by a pharmacological method and shows a significant reduction in the pronephric accumulation of $\mathrm{mA} \beta 42$ in the zebrafish $\mathrm{A} \beta$ clearance model that we developed, supporting the notion that that BLECs are one of the key components of the clearance system for $A \beta 42$ within the brain, selectively internalizing $\mathrm{mA} \beta 42$, but not $\mathrm{oA} \beta 42$, and removing it through the blood circulatory clearance route. 

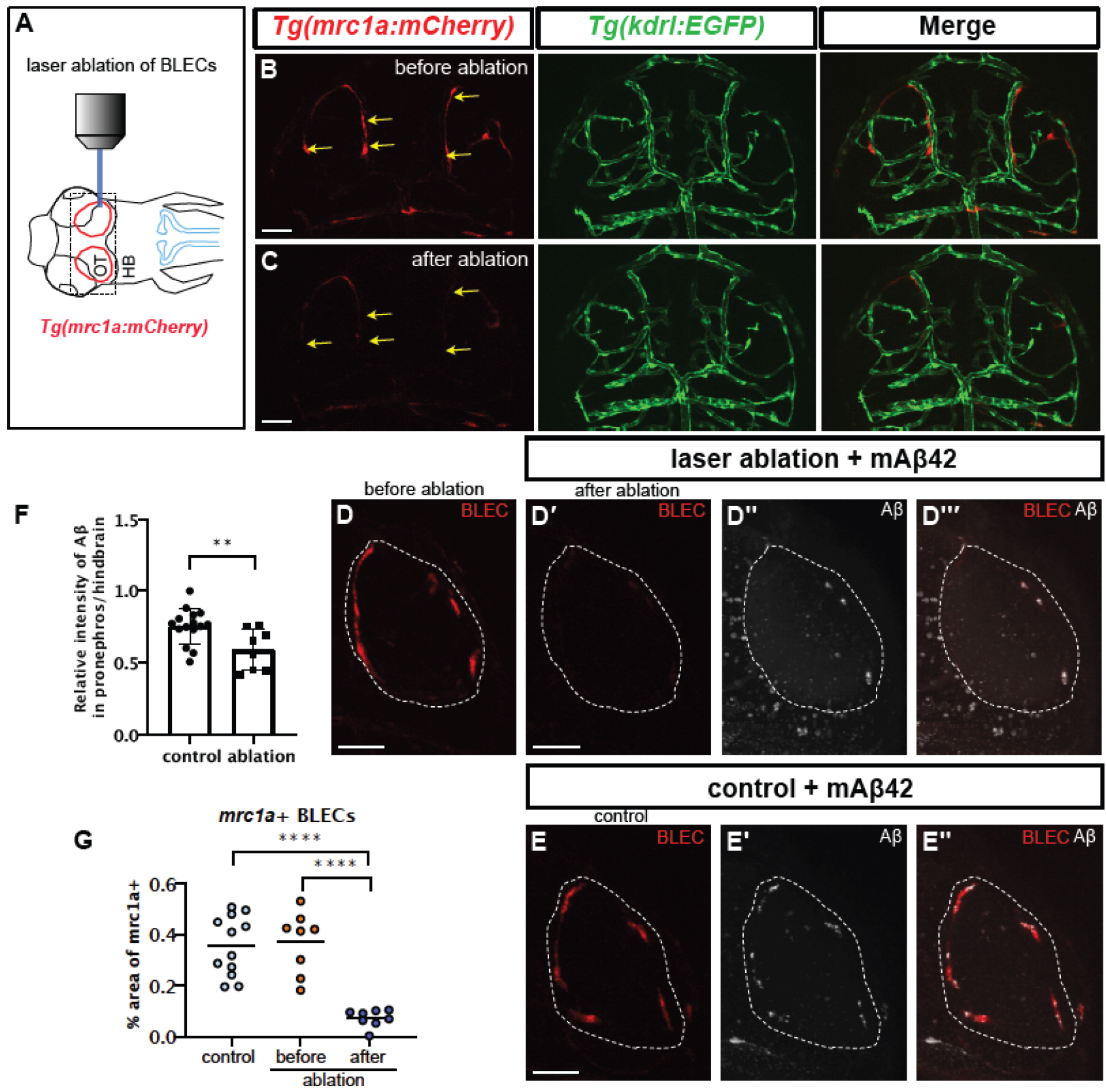

Figure 5. Selective ablation of BLECs decreased internalization of $\mathrm{mA} \beta 42$ and pronephric accumulation. (A) A schematic diagram of the experimental setting. BLEC-specific ablation using the confocal laser. (B,C) Confocal images of BLECs in the double transgenic $\mathrm{Tg}$ (mrc1a:mCherry); $\mathrm{Tg}(\mathrm{kdrl}: \mathrm{EGFP})$ at $3 \mathrm{dpf}$ before laser irradiation (B) and after ablation (C). Yellow arrows indicate the ablated BLECs. Scale bars $=50 \mu \mathrm{m}$. (D) Confocal images of mrc1a+ BLECs in the loop of the optic before ablation (D) and after ablation and mA $\beta 42$ injection $\left(\mathbf{D}^{\prime}-\mathbf{D}^{\prime \prime \prime}\right) .\left(\mathbf{D}^{\prime}\right)$ shows red channel, $\left(\mathbf{D}^{\prime \prime}\right)$ shows mA $\beta 42($ HiLyte647, white) and $\left(\mathbf{D}^{\prime \prime \prime}\right)$ is a merged image. Dotted lines denote the loop of BLECs. (E) Confocal images of mrc1a+ BLECs with

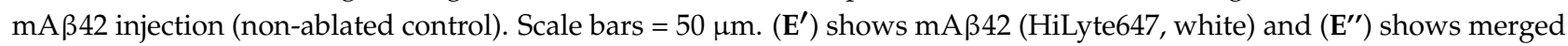
images of BLECs and $\mathrm{mA} \beta 42$. (F) Quantification of the relative intensity ratio between the pronephros and hindbrain. Data are presented as mean \pm SEM. Statistical significance was determined by two-tailed unpaired $t$-test. $n=15$ for non-ablated control, $n=8$ for ablated. $p=0.0092$. (G) Quantification of area fraction (\%) occupied by $m r c 1 a+$ BLECs. Data are presented as mean \pm SEM. Statistical significance was determined by ordinary one-way ANOVA with Tukey's test. ${ }^{* *}, p<0.01 ; * * * *$, $p<0.0001$. 

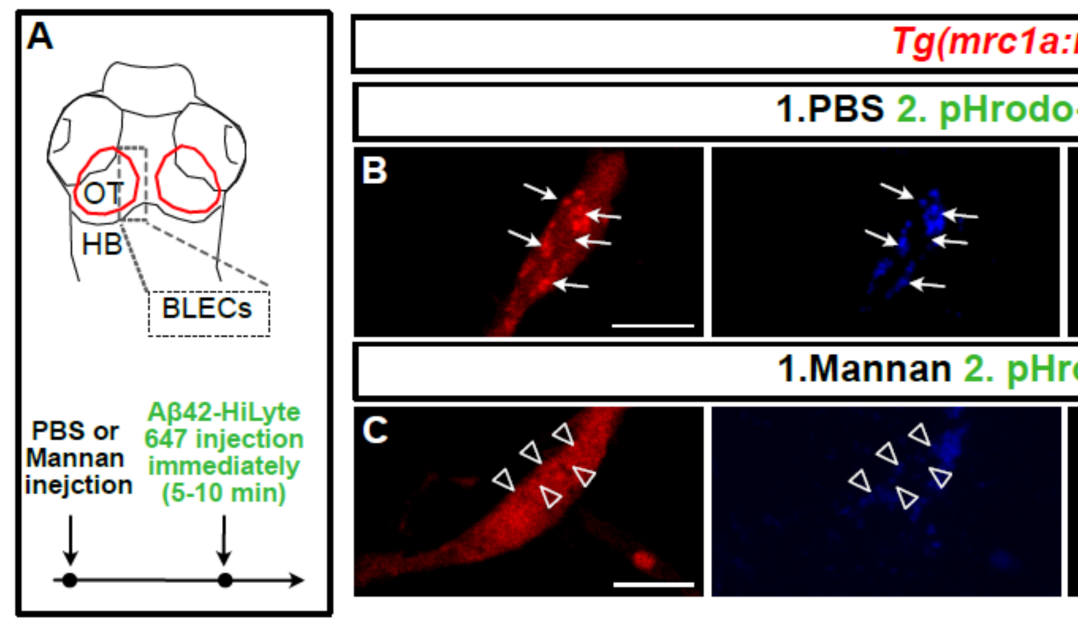

\section{a:mCherry)}
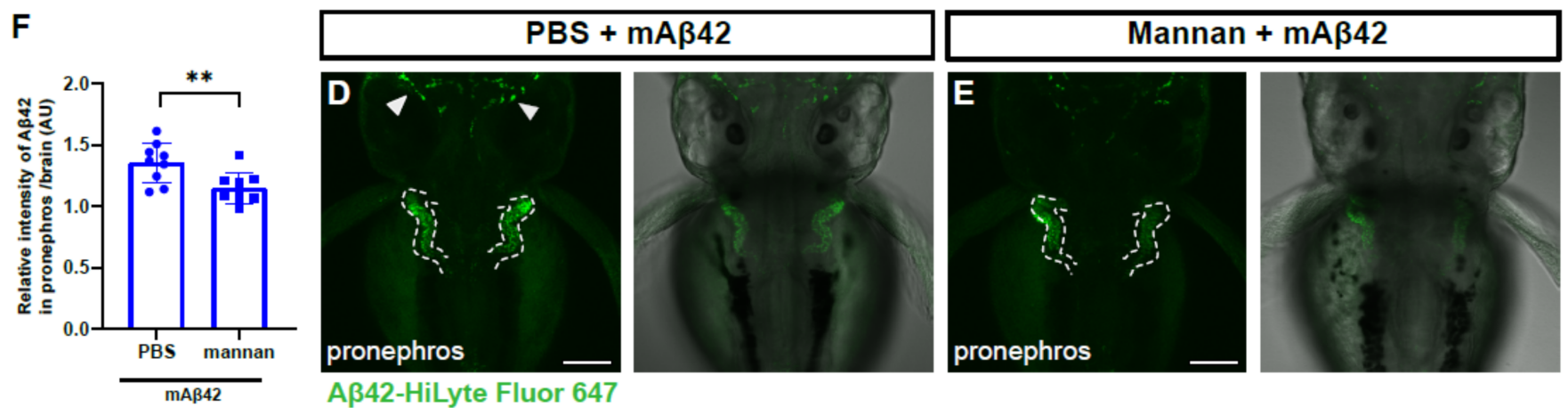

Figure 6. Mannan administration reduces uptake of $\mathrm{mA} \beta 42$ by BLECs and peripheral transport. (A) A schematic diagram of dorsal view of the $3 \mathrm{dpf}$ larval brain and the experimental setup. Dotted gray box denotes the region of interest. (B,C) Confocal images of mrc1a:mCherry+ BLECs co-injected with pHrodoGreen and mA $\beta 42$ (HiLyte Fluor 647). Arrows indicate colocalization of pHrodoGreen and mA $\beta 42$ (B). Empty arrowheads show that the mannan administration interferes with colocalization of pHrodoGreen and $\mathrm{mA} \beta 42$. Data are representative of at least three independent experiments. Scale bars $=10 \mu \mathrm{m}$. (D,E) Confocal images of the zebrafish pronephros after mA $\beta 42$ injection. Dotted lines depict the pronephros structure. Arrowheads indicate the accumulation of $\mathrm{mA} \beta 42$. Mannan treatment prior to $\mathrm{mA} \beta 42$ injection (E) resulted in a reduced pronephric accumulation compared to PBS control (D). Scale bars $=100 \mu \mathrm{m}$. (F) Quantification of the relative ratio of the intensity between the pronephros and brain. Statistical significance was determined by two-tailed unpaired $t$-test. $p=0.0092$. Data are presented as mean \pm SEM. $n=9$ per group. Data are representative of at least two independent experiments. ${ }^{* *}, p<0.01$.

2.6. An AB42 Aggregation Inhibitor Promotes oA 342 Localization into BLECs and the Peripheral Transport

In order to further confirm the functionality of BLECs in $\mathrm{mA} \beta 42$ clearance and assess the utility of our zebrafish model for validating an AD drug candidate, we tested the efficacy of the small molecule EPPS in A $\beta 42$ clearance, which is known to convert aggregated $A \beta$ into monomers and remove $\mathrm{A} \beta$ plaque and oligomers from the brain of an AD mouse model [34]. We explored whether EPPS treatment induced the localization change of oA $\beta 42$ into BLECs and facilitated their clearance out of the brain into the pronephros, presumably by converting oA $\beta 42$ into $\mathrm{mA} \beta 42$. First, oA $\beta 42$ (HiLyte Fluor 647) was injected into the brain., immediately followed by an EPPS incubation for the next $24 \mathrm{~h}$ and then the imaging of the BLEC loop from the optic tectum region with confocal microscopy (Figure 7A). Upon EPPS treatment, the co-localization of oA $\beta 42$ with BLECs was significantly increased in a dose-dependent manner compared to the vehicle-treated control (arrows in Figure 7B,C, F). High-resolution confocal imaging revealed the increased co-localization of oA $\beta 42$ in the internal components of the prox1a+ BLECs upon EPPS treatment (Figure 7D,E). We also examined whether the EPPS treatment enhanced the pronephric accumulation of oA $\beta 42$. Consistent with the increased co- 
localization of oA $\beta 42$ with BLECs, the EPPS treatment of oA $\beta 42$-injected larvae significantly increased the fluorescence intensity in the pronephros compared to the untreated oA $\beta 42-$ injected control (Figure 7G,H). The enhanced accumulation of oA $\beta 42$ in the pronephros with EPPS was verified by comparing the $A \beta 42$ fluorescence intensities of the pronephros relative to those of the brain (Figure $7 \mathrm{I}, \sim 23 \%$ increase, $p=0.0002$, two-tailed unpaired $t$ test, $n=10$ for control, $n=9$ for EPPS $250 \mathrm{mM}$ ). As expected, EPPS treatment in mA $\beta 42$ did not induce significant differences in the co-localization with BLECs, with a slight increase in the pronephric accumulation compared to the untreated control (Figure S8B-G). These data revealed the $A \beta 42$ clearance process of the candidate AD drug EPPS that was known to disaggregate oA $\beta 42$ and recover behavior defects in mouse models [34] by visualizing the increased relocalization of the disaggregated oA $\beta 42$ into BLECs for clearance. Therefore, improving the functionality of BLECs may be a novel therapeutic approach for treating AD by enhancing the efficient removal of $\mathrm{mA} \beta 42$ converted from $\mathrm{A} \beta 42$ aggregates and lowering $\mathrm{A} \beta$ toxicity in combination with $\mathrm{A} \beta 42$ disaggregating agents.
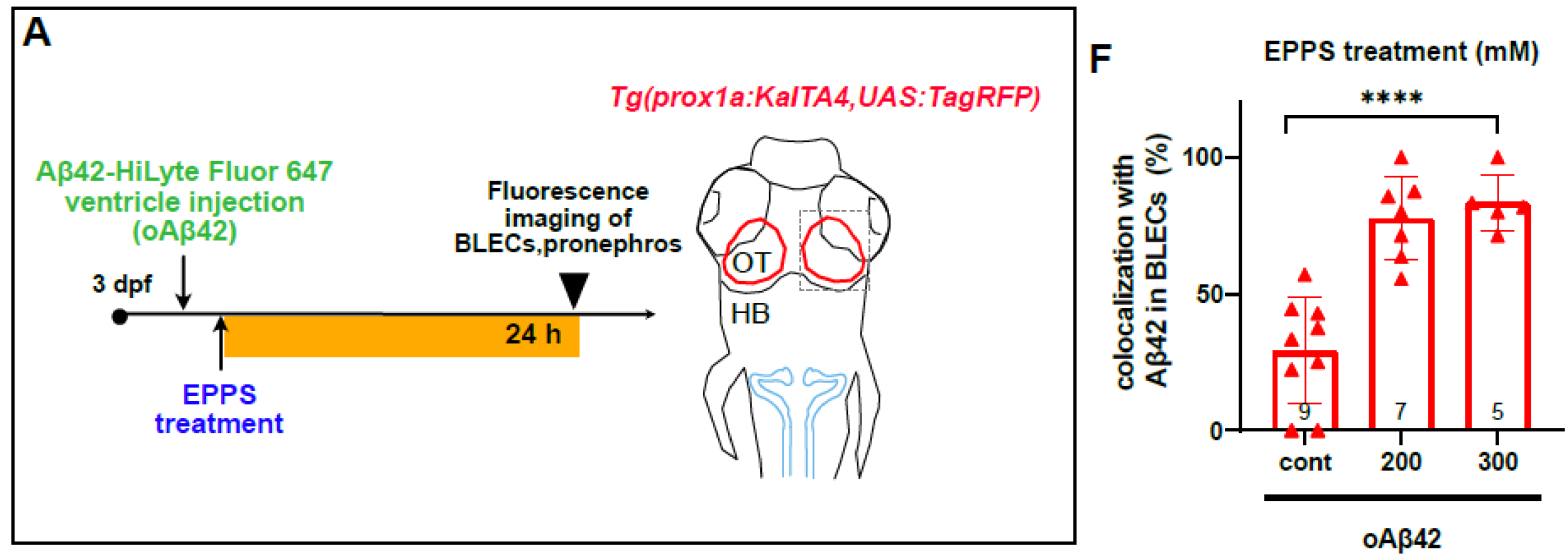

Tg(prox1a:KalTA4, UAS:TagRFP) Aß42-HiLyte Fluor 647

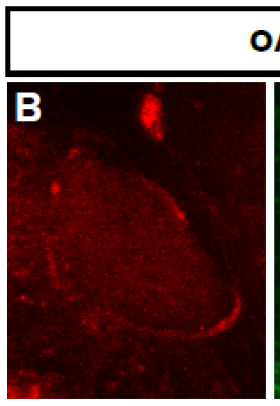

oA $\beta 42+$ control
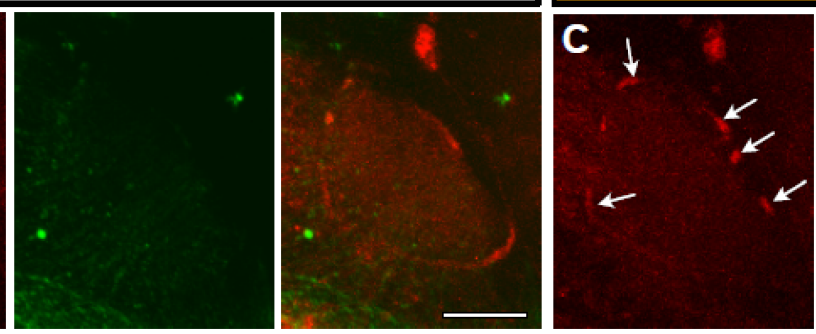

oA $342+$ EPPS $(200 \mathrm{mM})$

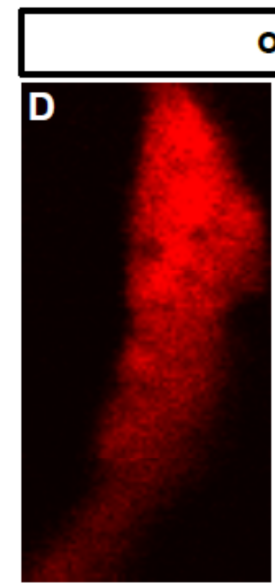

oA $342+$ control
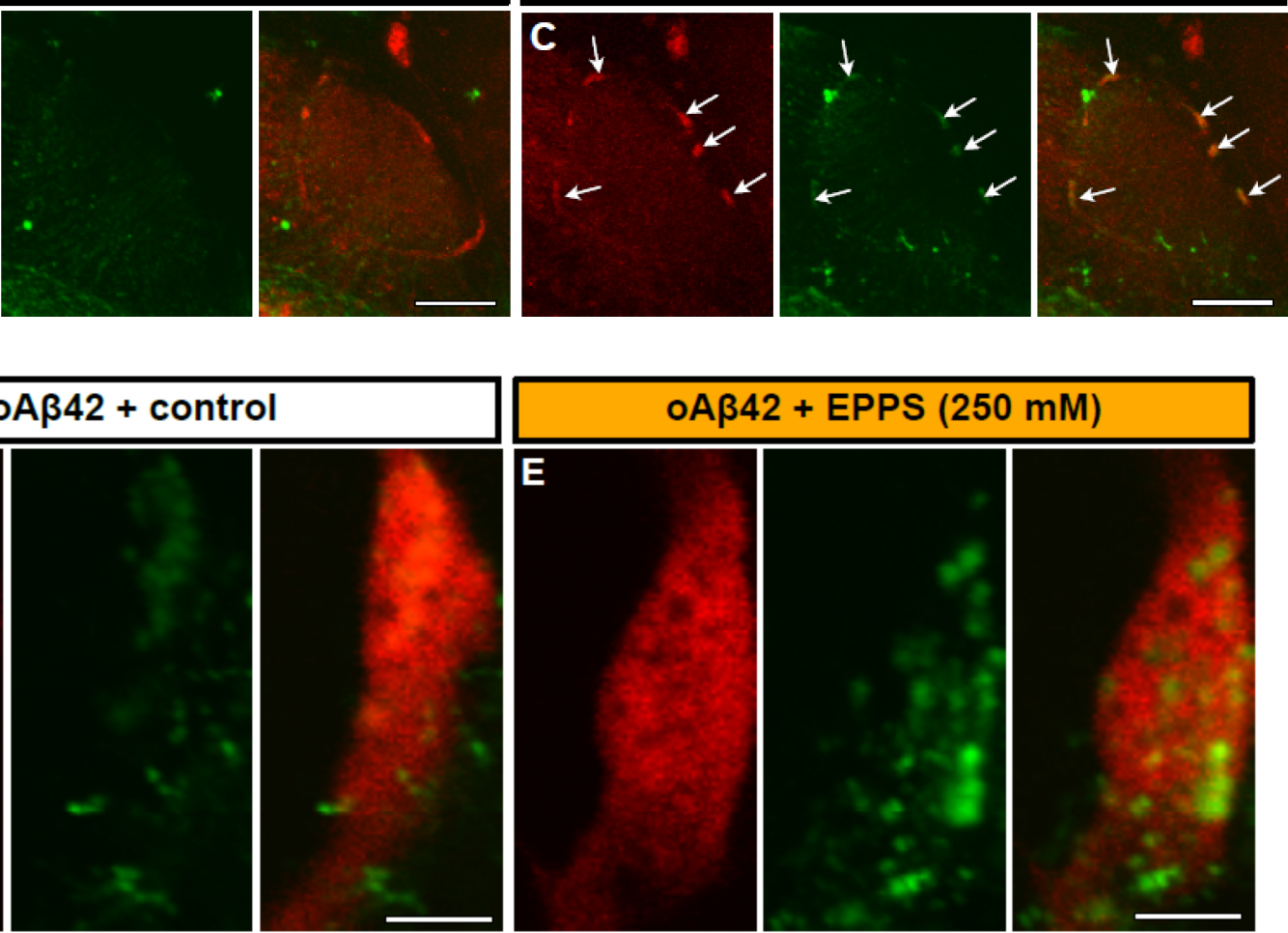

Figure 7. Cont. 


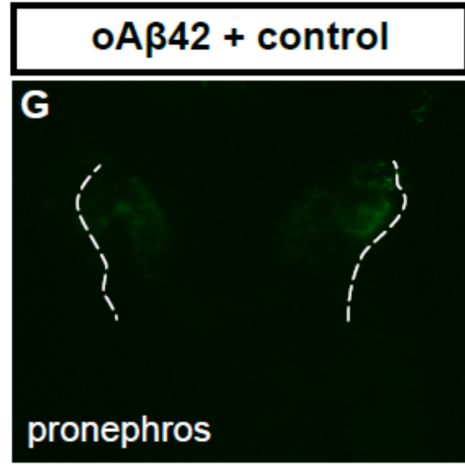

Aß42-HiLyte Fluor 647
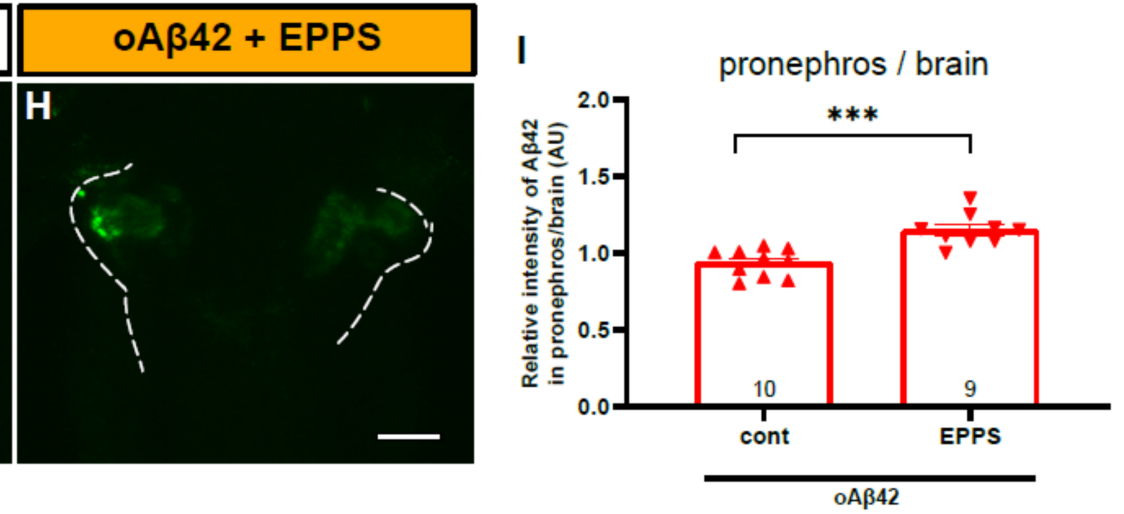

Figure 7. EPPS treatment enhances the BLEC localization and pronephric transport of oA $\beta 42$. (A) A schematic diagram of EPPS treatment after oA $\beta 42$ (HiLyte-Fluor 647) injection. Gray dotted box depicts the region of interest and blue lines indicate the pronephros. (B-E) Confocal images of prox1a:RFP+ BLECs in the loop of the optic tectum of oA $\beta 42$-injected larval brain with control (B,D) and EPPS treatment (C,E). (B,C) Co-localization of BLECs with oA $\beta 42$ increased upon EPPS treatment (arrows) in c compared to control (B). Scale bars in $(\mathbf{B}, \mathbf{C})=50 \mu \mathrm{m}$. (D,E) Confocal images of prox1a:RFP+ BLECs with EPPS treatment $(250 \mathrm{mM}, \mathbf{e})$ after oA $\beta 42$ injection with high magnification revealed the internalized oA $\beta 42$ in BLECs compared to control (D). Scale bars in (D,E) $=5 \mu \mathrm{m}$. (F) Quantification of oA $\beta 42$ co-localization in BLECs (\%) upon EPPS treatment. Statistical significance was determined by ordinary one-way ANOVA with Tukey's test. (G,H) Confocal images of the pronephros (white dotted lines) injected with oA $\beta 42$ in control (G) and with EPPS treatment for $24 \mathrm{~h}(\mathbf{H})$. (I) Quantification of the relative ratio of the intensity between the pronephros and brain. Two-tailed unpaired $t$-test, $p=0.0002$. Data are presented as mean \pm SEM. Data are representative of at least two independent experiments. Numbers within bar bottom graphs represent $n .^{* * *}, p<0.001 ;{ }^{* * * *}, p<0.0001$.

\section{Discussion}

The initial accumulation and defective clearance of $A \beta$ are considered as early phases of AD before clinical symptoms appear [35]. In the current study, we established an in vivo zebrafish model to investigate the brain clearance system regarding the accumulation of $A \beta 42$, which is one of the main $A \beta$ isoforms and displays a strong neurotoxicity. In this model, we visualized and monitored the real-time, in vivo localization and clearance of $A \beta 42$ in the brain, by injecting fluorescently labeled $A \beta 42$ peptides into the ventricle of the zebrafish larval brain, revealing the differential clearance dynamics of $A \beta 42$ from the brain depending on its aggregation status (i.e., $\mathrm{mA} \beta 42$ and $\mathrm{oA} \beta 42$ ). We found that this differential clearance was mediated by BLECs, a recently re-identified lymphatic cell population in the brain. BLECs participated in the selective internalization of $A \beta 42$ monomers, but not $A \beta 42$ oligomers, and cleared them through the blood circulatory clearance pathway, resulting in the accumulation of $\mathrm{mA} \beta 42$ in the pronephros for excretion. The role of BLECs in clearing $\mathrm{mA} \beta 42$ was functionally validated by genetic depletion, pharmacological inhibition, or specific ablation using laser-targeting BLECs that prevented the efficient clearance of $\mathrm{mA} \beta 42$ from the brain and, conversely, by the promoted clearance of oA $\beta 42$ with EPPS treatment, a protein-disaggregating agent that facilitates the conversion of oA $\beta 42$ to $\mathrm{mA} \beta 42$. Taken together, our data suggest that BLECs are one of the main components in $A \beta 42$ homeostasis in the brain clearance system. We propose that the dysfunction of BLECs is a causative factor in AD pathogenesis and the recovery and/or enhancement of BLEC function, especially in combination with an $A \beta$ disaggregation strategy, as a legitimate therapeutic and diagnostic approach against pathological $\mathrm{A} \beta 42$ accumulation.

\subsection{Cerebroventricular Injection of A $\beta$ for Modeling Alzheimer's Disease in Zebrafish}

Previous studies utilized direct $A \beta$ injection methodology to generate AD-like symptoms in mouse models because of the rapid induction of phenotypes and for economic reasons $[20,36]$. Similarly, a few zebrafish $A \beta$ injection models were established to validate a chaperone-gold nanoparticle as a novel $\mathrm{AD}$ drug that mitigated $\mathrm{A} \beta$ toxicity and $\mathrm{AD}$-like 
behavioral defects in the larval and adult stages, to identify upregulated intereleukin- 4 that activated neural stem cell proliferation for regeneration after $A \beta$-induced neuronal death in the adult brain, and to study the function of $A \beta$ oligomers and distinct molecular pathways in the sleep/wake regulation with a zebrafish larval model [37-39]. All of these studies indicated the applicability of the direct $\mathrm{A} \beta$ injection strategy in zebrafish $\mathrm{AD}$ modeling. In line with these studies, we successfully established a cerebroventricular $A \beta 42$ injection model for the early larval stages (3 4 dpf), when the externally located zebrafish larval brain is transparent and accessible. This allows a direct in vivo live imaging with a high resolution and readily amenable genetic/chemical manipulations via a direct injection in a fast and cost-effective way. With our A $\beta 42$ injection model, we addressed for the first time the mechanistic aspects of $A \beta 42$ clearance in the brain depending on their aggregation status by the selective nature of BLECs, an under-studied lymphatic cell population in the brain. Our model provides a useful platform to investigate the underlying mechanisms of $\mathrm{A} \beta$ dynamics in the brain, as well as to validate candidate modifiers (genes and chemicals) of AD-like phenotypes in vivo in great detail.

\subsection{BLEC Is a Novel Component of the Brain Clearance System to Remove $m A \beta 42$}

The proteins in the brain can be removed by various clearance mechanisms [6]. Generally, extracellular proteins such as $A \beta$ in the CSF can be cleared by absorption into the circulatory system, including via the blood-CSF barrier (BCSFB) or from the meningeal lymphatic vessels to the cervical lymph node [6]. The latest findings of meningeal lymphatic vessels in mammals are broadening our understanding of how the brain maintains a fluid balance and removes cellular waste; in mammals, the meningeal lymphatic vessels, particularly in the basal part of the skull (the basal meningeal lymphatic vessels), drain CSF and clear macromolecules with their specialized morphologies [13]. The CSF in the basal meningeal lymphatic vessels drains into the cervical lymph nodes, shown by macromolecular tracers [13]. The ablation of meningeal lymphatic vessels, ageing, or a disease context such as in an AD mouse model, impaired these effluxes [12,13]. The solutes in the cervical lymph nodes are likely to be transported into the blood and degraded in the liver or kidney [6,24]. Consistent with the mammalian system, zebrafish were recently found to possess a meningeal lymphatic network with draining function at juvenile and adult stages [40], although the exact drainage spots for meningeal lymphatics, whether the CSF directly drains into the blood vessel or other lymphatic network, or whether an undiscovered cervical lymph node exists as in mammals, remain to be addressed. In the current study, we focused on the BLECs as one of the components of the brain clearance system in zebrafish. Although BLECs have a lymphatic identity, they do not form lumen and are loosely connected with the surrounding cerebrovasculature, unlike meningeal lymphatic vessels. In addition, their locations in the meninges are quite distinct because BLECs are localized in the deeper layer of the mouse brain (leptomeninges, the arachnoid, and the pia mater) and adjacent to the cerebral blood vessels [13-15], whereas meningeal lymphatic vessels are located in the outer layer of meninges both in mouse (dura mater) and zebrafish (below the skull) $[17,40]$. Since BLECs are a sort of cell population clearly distinct from meningeal lymphatic vessels in many aspects as described above, BLECs may not be directly implicated in the drainage of the general lymphatic system in the brain at present. As our current studies reveal an A $\beta$ clearance pathway mediated by BLECs from the brain to the peripheral tissues, further study is required to clarify the functional linkage between BLECs and meningeal lymphatics in the juvenile or adult stages of zebrafish.

BLECs were originally discovered as fluorescent granule perithelial cells (FGPs) in mammals in the 1980s [41] and recently re-identified in zebrafish, with a diverse naming as brain/mural lymphatic endothelial cells (BLECs/muLECs), FGPs, or Mato cells; they have unusual characteristics, such as a macrophage-like morphology, lymphatic lineage, and unique locations in the perivascular area [14-16]. Since there are still no specific markers for the BLECs, it is currently difficult to distinguish the BLECs from the CNS macrophages, which also express the lymphatic markers such as Mrc1 and Lyve1 (lym- 
phatic vessel endothelial hyaluronic acid receptor 1) [42]. Thus, the presence and identity of BLECs in mammals still remain controversial among researchers, as well as whether the LLECs (murine BLECs) are a distinct cell type from other cells such as perivascular macrophages or FGPs, warranting further comprehensive studies in both mammals and zebrafish with in-depth comparative approaches based on detailed anatomical, molecular, and transcriptomic analyses.

Notably, FGPs (also called Mato cells) in mouse and rat models are reported to be implicated in the pathogenesis of cerebral amyloid angiopathy (CAA), in which the aberrant deposition of $\mathrm{A} \beta$ in blood vessel walls are frequently detected in the leptomeningeal and cortical arteries [42,43]. Several studies suggested that the uptake capacity of FGPs in the cerebral vessels is affected by aging, using electron microscope observations [41,44], while other correlative studies suggested the correlation of the vesicular uptake of perivascular macrophages with the onset of AD [41,44,45]. Furthermore, the functional contribution of perivascular macrophages to CAA was suggested based on the finding that the depletion of perivascular macrophages in an $\mathrm{AD}$ mouse model resulted in $\mathrm{A} \beta$ deposition along the vasculature [46], although the distinction between the macrophages and FGPs is not clear in this study. As there is still no direct evidence or association of BLECs with mammalian diseases such as AD or CAA, our findings on the BLECs-mediated blood circulatory clearance of $A \beta$ may be represented as indirect evidence for the implication of BLECs in CAA, regardless of whether BLECs are unique cell populations distinct from FGPs, as Shibata-Germanos suggested [17], or one of the subpopulations of FGPs [15,40].

\subsection{BLECs Selectively Clear Monomeric A $\beta$ from Brain with a Blood Circulatory Route}

Sporadic AD patients exhibit an impairment in $A \beta$ peptide clearance rather than production $[3,47]$. In addition, several risk genes associated with sporadic $A D$ are also thought to affect $A \beta$ clearance $[48,49]$. These findings illustrate the importance of understanding and targeting the brain clearance system to develop an efficacious AD therapy. The decreased clearance of $A \beta$ results in the accumulation of various isoforms of $A \beta$ monomers and their aggregation into oligomers, fibrils, and plaques in the central nervous system [47]. Despite the pathological relevance and toxicity of oA $\beta$, little is known about how it is cleared from the brain. A handful of $\mathrm{AD}$ mouse model studies suggested that $\mathrm{oA} \beta$ may be less efficiently cleared from the brain due to its nature of resisting enzymatic degradation in the brain or its increased molecular size preventing glymphatic transport $[10,22]$. In the current study, the comparison of monomeric and oligomeric $A \beta 42$ clearance using our zebrafish model revealed that $\mathrm{mA} \beta 42$ readily interacted with and accumulated in BLECs, a less-characterized clearance component in the brain used for efficient clearance. On the contrary, oA $\beta 42$ rarely accumulated in BLECs, which contributed to its preferential accumulation in the brain.

Given the role of BLECs in the internalization and clearance of macromolecules in the brain, we hypothesized that BLECs were implicated in the A $\beta 42$ clearance from the brain and aimed to elucidate their precise function in the clearance of differently aggregated forms of $A \beta 42$ peptides. Our data suggest that BLECs are one of the critical components for $A \beta$ clearance as they selectively internalize $\mathrm{mA} \beta 42$. Distinct from the recently discovered meningeal lymphatic vessels in the zebrafish brain after the juvenile stages (initially developed after 9 10 dpf [40]), BLECs appear to play a role in drainage function, at least during the larval stages of zebrafish. This conclusion was based on the findings that (i) BLECs readily internalized the ventricle-injected $\mathrm{mA} \beta 42$ and then delivered it to the periphery as shown in the accumulation in the pronephros (Figures 2 and 3), (ii) BLECs-accumulated $\mathrm{mA} \beta 42$ fluctuated dynamically and disappeared in real time in vivo (Figure 3 and Figure S7; Supplementary Video S1), and (iii) abrogating BLEC function by the depletion with ccbe1 knockdown, laser ablation or mannan delivery into the brain prior to $\mathrm{mA} \beta 42$ injection resulted in the failure of $A \beta$ clearance to the periphery (Figures 4-6). 
We also showed that the pronephric accumulation of $\mathrm{mA} \beta 42$ was based on the blood circulatory route with propranolol and tnnt2a morphants (Figure 2). Although the genetic depletion of BLECs by ccbe1 $\mathrm{MO}$ resulted in a reduced pronephric accumulation of $\mathrm{mA} \beta 42$ up to $\sim 35 \%$ decline (Figure 4 ), the specific laser ablation of BLECs showed a $\sim 21 \%$ reduction in the pronephric delivery (Figure 5). This may suggest that BLECs are only partly responsible for the blood circulatory clearance of $\mathrm{mA} \beta 42$ and, although additional clearance routes exist, we cannot currently exclude the possibility of the incomplete ablation of BLECs.

The exact clearance mechanisms of BLECs in clearing $\mathrm{mA} \beta 42$ via the blood circulatory route is still unclear. It was reported that $A \beta$-bearing perivascular monocytes played a role in $A \beta$ clearance via crawling veins and circulated back into the blood with $A \beta$ [50], suggesting that the $A \beta$-scavenging cells such as monocytes, not only degrade $A \beta$ intracellularly, but also contribute to blood circulatory clearance. It is possible that BLECs may clear $\mathrm{mA} \beta 42$ in a similar fashion via the interaction of nearby vasculatures, in a similar way to perivascular monocytes, although we could not observe such cellular movement of BLECs in our time-lapse imaging (Figure S7; Supplementary Video S1). Alternatively, it may be also feasible that the extracellular vesicles and exosomes may be released and taken up between the BLECs and endothelial cells, similar to the cell-to-cell communicating process known to occur among diverse cell types composing the neurovascular unit [51].

Interestingly, the injected oA $\beta 42$ (with predicted sizes in the aqueous buffer of $100-300 \mathrm{kDa}$ [4]), failed to be internalized by BLECs (Figure 3), despite the fact that BLECs have the capability of internalizing macromolecules of up to $500 \mathrm{kDa}$ [16]. This discrepancy may be due to the distinct characteristics of $A \beta$ oligomers, such as their unique and various structural natures, rather than their size per se [52]. This failure of oA $\beta 42$ clearance was significantly reversed by treating the BLECs with the A $\beta$-disaggregating agent EPPS with an increased pronephric delivery (Figure 7), thereby illustrating the therapeutic benefit of an $A \beta$-disaggregating agent on toxic oA $\beta$ clearance. Curiously, $A \beta$ disaggregated by EPPS may re-form A $\beta$ aggregates in the absence of a proper clearance system or immune responses to remove the disaggregated A $\beta$, as shown in an AFM study with EPPS [53]. Thus, the improvement of the brain clearance system via the enhanced functionality of BLEC s coupled with $A \beta$ disaggregation would provide an efficient therapeutic strategy to prevent $\mathrm{AD}$ pathogenesis by reducing the accumulation of the toxic $\mathrm{A} \beta$ oligomers in the brain.

\section{Materials and Methods}

\subsection{Animals}

Zebrafish (Danio rerio) AB strain and transgenic lines were kept at $28.5^{\circ} \mathrm{C}$ in $14 \mathrm{~h}$ light and $10 \mathrm{~h}$ dark cycle. The lymphatic system was visualized using $\operatorname{Tg}\left(\operatorname{prox} 1 a^{B A C}\right.$ : KalTA4-4xUAS-E1b:uncTagRFP) [29] (herein denoted as Tg(prox1a:KalTA4, UAS:TagRFP; kindly provided by Prof. Suk-Won Jin). Blood vessels were visualized with $T g(k d r l: E G F P)$ and $T g(f l i 1 a: E G F P)$. To generate BLEC- and lymphatic vasculature-specific transgenic zebrafish, $\operatorname{Tg}$ (mrc1a:mCherry) was newly generated according to a previous study [54]. Briefly, $2.1 \mathrm{~kb}$ genomic sequence upstream from the transcription start site of zebrafish mrc1a gene, combined with $0.3 \mathrm{~kb}$ enhancer sequence located in intron 20, was cloned into pTol2 vector using Gibson assembly (New England Biolabs, Ipswich, MA, USA). Tol2-based mrc1a:mCherry expression construct was prepared using plasmid endotoxin free mini kit (Geneaid, New Taipei City, Taiwan) following the manufacturer's protocol. To generate transgenic zebrafish, one-cell-stage eggs were injected with approximately $1 \sim 2 \mathrm{~nL}$ of a DNA/RNA solution containing $25 \mathrm{ng} / \mu \mathrm{L}$ Tol2 transposase mRNA and $20 \mathrm{ng} / \mu \mathrm{L}$ Tol2-based Mrc1a:mCherry expression construct [55]. The embryos showing targeted tissuespecific fluorescence were screened and raised to the adulthood. The F0 adult fish were crossed to WT fish for analyzing germline transmission by screening the offspring under the M205FCA microscope (Leica, Wetzlar, Germany). To avoid pigmentation, embryos were treated with $0.003 \%$ 1-phenyl-2-thiourea (PTU) (Sigma, St. Louis, MO, USA) in E3 egg water $\left(5 \mathrm{mM} \mathrm{NaCl}, 0.17 \mathrm{mM} \mathrm{KCl}, 0.33 \mathrm{mM} \mathrm{CaCl}_{2}\right.$, and $\left.0.33 \mathrm{mM} \mathrm{MgSO}_{4}\right)$. All animal 
experiments were carried out in accordance with permits and guidelines of the Korea Research Institute of Bioscience and Biotechnology (KRIBB) and approved by KRIBBIACUC (approval number: KRIBB-AEC-20200).

\subsection{A $\beta$ preparation and Ventricle Microinjection}

Fluorescence (HiLyte Fluor 488, 555, 647)-labeled amyloid- $\beta$ (1-42) (DAEFRHDSGYEVHHQKLVFFAEDVGSNKGAIIGLMVGGVVIA) peptides were purchased from AnaSpec (Fremont, CA, USA). A $\beta$ was diluted with DMSO at $2 \mu \mathrm{g} \mu \mathrm{L}^{-1}$ and stored at $-80{ }^{\circ} \mathrm{C}$ deep freezer before use. HiLyte-conjugated $A \beta(1-42)$ stock solution was diluted in 1XPBS (phosphate-buffered saline) $(1: 9 v / v)$ and the oligomeric form of $\mathrm{A} \beta$ was prepared by incubating at $37^{\circ} \mathrm{C}$ for 3 days as previously described [20]. The monomeric form of $\mathrm{A} \beta$ was immediately used without incubation. Microinjections were carried out with a Pneumatic PicoPump (World Precision Instruments, Sarasota, FL, USA) and capillary needles prepared by a Micropipette puller (Sutter instrument, Novato, CA, USA). For ventricle injection, $3 \mathrm{dpf}$ larvae were anesthetized with tricaine (Sigma, St. Louis, MO, USA) and placed in 1\% low-melting agarose confocal dish and injected with the total volume of $1-2 \mathrm{~nL}$ of the $\mathrm{A} \beta$ solution. Trimmed needles were inserted into the ventricular space between the optic tectum and hindbrain, in order to not penetrate into deep brain tissues.

\subsection{Confocal Microscopic Analyses for A $\beta$ Clearance and Quantification}

For live confocal imaging of zebrafish larvae, $3 \mathrm{dpf}$ or $4 \mathrm{dpf}$ larvae were anesthetized with tricaine and mounted in $1 \%$ low-melting agarose on confocal dishes. Then, the agarose was covered with tricaine solution. Confocal $Z$ step size was at $4 \sim 5 \mu \mathrm{m}$ with $20 \times$ objective lens and $Z$ projections were generated by stacking 25 optical slices for the brain region and 20 optical slices for the pronephros region, using FV1000 confocal microscope (Olympus, Tokyo, Japan) or Zeiss LSM800 microscope (Carl Zeiss, Oberkochen, Germany). Z projection images of injected $A \beta 42$ fluorescence in the brain were converted to thresholded (pixel intensity, 40-255) images, and areas of particles in calibrated square unit $(512 \times 512$ pixels $)$ were measured as a percentage using Image J (National Institute of Health, Bethesda, Maryland, MD, USA, https://imagej.nih.gov/ij/ (accessed on 8 October 2021), v1.52, accessed on 1 August 2021). Clearance index was determined by following formula ("reduction rate" $(\%)=$ particle area of fluorescence at $5 \mathrm{hpi}$-particle area of fluorescence in $24 \mathrm{hpi} /$ particle area of fluorescence in $5 \mathrm{hpi}$ ). The A $\beta 42$ fluorescence intensity of the pronephros was measured in the region of interest and analyzed using Image J. The A $\beta 42$ fluorescence intensity of each pronephros was measured and normalized by background signals in non-fluorescence area and presented as fold differences using Image J. The relative $A \beta 42$ intensity of each pronephros to the brain was also calculated by dividing the $A \beta 42$ intensity of the pronephros by the mean fluorescence intensity of each brain. Quantification of A $\beta 42$ co-localization with BLECs was presented as percentages of the number of $A \beta 42$ positive BLECs over the whole number of BLECs.

\section{4. pHrodoGreen Injection}

To validate the internalization of BLECs, an endocytic marker, pHrodoGreen dextran, $10 \mathrm{kDa}$ (ThermoFischer, Waltham, MA, USA, P35368) was prepared in PBS at $2 \mathrm{mg} / \mathrm{mL}$ concentration and injected into the brain ventricle of $3 \mathrm{dpf}$ zebrafish larvae $[16,18]$ before $\mathrm{mA} \beta 42$ or $\mathrm{oA} \beta 42$ was introduced. In the mannan experiment, pHrodoGreen was injected after PBS or mannan administration.

\subsection{Genetic and Pharmacological Inhibition of Heartbeat}

To reduce the heartbeat in $\mathrm{mA} \beta 42$-injected zebrafish larvae, $100 \mu \mathrm{M}$ of propranolol, a $\beta$-blocker (Sigma, St. Louis, MO, USA), was incubated for $4 \mathrm{~h}$ at $3 \mathrm{dpf}$ larvae or $200 \mu \mathrm{M}$ of tnnt2a morpholino (tnnt2a ATG MO 5'-CAT GTT TGC TCT GAT CTG ACA CGC A) 
was injected at one cell stage [27]. The heartbeat was counted for $10 \mathrm{~s}$ and extrapolated. Pronephros imaging was conducted in 1\% low-melting agarose containing the propranolol.

\subsection{Intravenous Injection of Endocytic Tracer}

To verify vascular route of $\mathrm{mA} \beta 42$ and visualize the pronephros in our model, intravenous injection of endocytic tracer was performed as previously described [28]. $10 \mathrm{kDa}$ dextran labelled with Alexa Fluor 647 (ThermoFisher, Waltham, MA, USA, D22914) was prepared in PBS at $2 \mathrm{mg} / \mathrm{mL}$ final concentration and injected into caudal vein of $3 \mathrm{dpf}$ zebrafish larvae into the brain ventricle of which mA $\beta 42$ or oA $\beta 42$ was injected at $3 \mathrm{dpf}$. For sectioning of the pronephros region, larvae were mounted in cryosectioning molds, frozen on dry ice, and sectioned using a Leica CM1860 cryostat (Leica, Wetzlar, Germany).

\subsection{Genetic and Pharmacological Inhibition of Brain Lymphatic Endothelial Cells}

Morpholino oligonucleotides (ccbe1 ATG MO 5'-CGG GTA GAT CAT TTC AGA CAC TCT G-3'; control MO 5'-CCT CTT ACC TCA GTT ACA ATT TAT A-3') [32] were purchased from Gene Tools (Philomath, OR, USA) and diluted in nuclease free water to make $1 \mathrm{mM}$ stock. The prepared morpholinos were injected at one to four cell stages at a concentration of $500 \mu \mathrm{M}$ with $0.25 \%$ phenol red (Sigma, St. Louis, MO, USA) using a Pneumatic PicoPump. To interfere with the mannose receptor-dependent endocytosis of BLECs, mannan (Sigma, St. Louis, MO, USA) (50 mg/mL, in PBS) was injected into the larval brain ventricle 10 min prior to $A \beta 42$ injection.

\subsection{Laser Ablation of Brain Lymphatic Endothelial Cells}

Laser ablation of BLECs was performed according to a previous study based on confocal microscope laser ablation with several modifications [33]. Tg(mrc1a:mCherry) larvae were raised in PTU until $3 \mathrm{dpf}$ and mounted in the 1\% low-melting agarose. mrc1a:mCherrypositive cells in the zebrafish brain were ablated using a $405 \mathrm{~nm}$ laser of confocal microscope (FV1000 confocal microscope, Olympus, Tokyo, Japan). Briefly, using the 60x oil immersion objective a cell body of BLECs was positioned in the center for ablation. The laser power of $405 \mathrm{~nm}$ was adjusted to $100 \%$ and the scanning mode was activated during $90 \mathrm{~s}$. Because the whole BLEC ablation process for a larva takes approximately $40 \mathrm{~min}-1 \mathrm{~h}$, BLECs of only two to three samples could be ablated for a single set of experiments due to time constraints, the statistical significance was determined by sum of three independent experiments performed with the identical experimental settings. Larvae were imaged first before ablation, followed by $\mathrm{mA} \beta 42$ injection, and then another round of imaging for pronephric accumulation measurement after ablation.

\subsection{EPPS Treatment}

For A $\beta$ disaggregation, EPPS [4-(2-hydroxyethyl)-1-piperazinepropanesulfonic acid] was purchased (Sigma, St. Louis, MO, USA) [34]. EPPS solution was prepared as $1 \mathrm{M}$ stock by dissolving with distilled water. EPPS was added to PTU E3 egg water up to 200-300 mM and incubated for $24 \mathrm{~h}$ after A $\beta 42$ injection. EPPS-treated larvae were mounted in the low-melting agarose for imaging.

\subsection{Statistical Analysis}

All statistical calculations and analyses were performed using Prism (Version 8.4.2, GraphPad, San Diego, CA, USA). Statistics were performed using an unpaired $t$ test or ordinary one-way ANOVA. Data were represented as mean \pm standard error of the mean $( \pm S E M)$.

Supplementary Materials: The following are available online at https:/ /www.mdpi.com/article/10 $.3390 /$ ijms222111883/s1. 
Author Contributions: Conceptualization, J.-S.L. and Y.-M.J.; data analysis, Y.-M.J., J.-G.L., H.-J.C., W.S.L. and J.J.; funding acquisition, J.-S.L.; methodology, Y.-M.J.; writing and editing, J.-S.L. and Y.-M.J. All authors have read and agreed to the published version of the manuscript.

Funding: This work was supported by the National Research Foundation (NRF) and National Research Council of Science and Technology (NST), Ministry of Science and ICT, Korea (NRF2019R1A2C1010661, CRC-15-04-KIST, NRF-2018R1A6A3A01011728), and the KRIBB Research Initiative Program (KGM5352113, KGM2112133).

Institutional Review Board Statement: This study was conducted according to permission and guidelines of the Korea Research Institute of Bioscience and Biotechnology (KRIBB) and approved by KRIBB-IACUC (approval number: KRIBB-AEC-20200).

Informed Consent Statement: Not applicable.

Data Availability Statement: The data presented in this study are available on request from the corresponding author.

Acknowledgments: We thank Kweon Yu (KRIBB), Kyu-Sun Lee (KRIBB) and the lab members for helpful discussions.

Conflicts of Interest: The authors declare no conflict of interest.

$\begin{array}{ll}\text { Abbreviations } \\ \text { A } \beta & \text { amyloid beta } \\ \text { AD } & \text { Alzheimer's disease } \\ \text { AFM } & \text { atomic force microscopy } \\ \text { BBB } & \text { blood-brain barrier } \\ \text { BLEC } & \text { brain lymphatic endothelial cells } \\ \text { CSF } & \text { cerebrospinal fluid } \\ \text { FGPs } & \text { fluorescent granule perithelial cells } \\ \text { ISF } & \text { interstitial fluid } \\ \text { mA } \beta 42 & \text { monomeric A } \beta 42 \\ \text { oA } \beta 42 & \text { oligomeric } A \beta 42\end{array}$

\section{References}

1. Long, J.; Holtzman, D.M. Alzheimer Disease: An Update on Pathobiology and Treatment Strategies. Cell 2019, 179, 312-339. [CrossRef] [PubMed]

2. Thal, D.R. Clearance of Amyloid Beta-Protein and its Role in the Spreading of Alzheimer's Disease Pathology. Front Aging Neurosci. 2015, 7, 25. [CrossRef] [PubMed]

3. Selkoe, D.J.; Hardy, J. The Amyloid Hypothesis of Alzheimer's Disease at 25 years. EMBO Mol. Med. 2016, 8, 595-608. [CrossRef] [PubMed]

4. Cline, E.N.; Bicca, M.A.; Viola, K.L.; Klein, W.L. The Amyloid-Beta Oligomer Hypothesis: Beginning of the Third Decade. J Alzheimers Dis. 2018, 64, S567-S610. [CrossRef]

5. Ramusino, M.C.; Garibotto, V.; Bacchin, R.; Altomare, D.; Dodich, A.; Assal, F.; Mendes, A.; Costa, A.; Tinazzi, M.; Morbelli, S.D.; et al. Incremental Value of Amyloid-PET versus CSF in the Diagnosis of Alzheimer's Disease. Eur. J. Nucl. Med. Mol. Imaging 2020, 47, 270-280. [CrossRef]

6. Xin, S.-H.; Tan, L.; Cao, X.; Yu, J.-T.; Tan, L. Clearance of Amyloid Beta and Tau in Alzheimer's Disease: From Mechanisms to Therapy. Neurotox. Res. 2018, 34, 733-748. [CrossRef]

7. Tarasoff-Conway, J.M.; Carare, R.O.; Osorio, R.; Glodzik, L.; Butler, T.; Fieremans, E.; Axel, L.; Rusinek, H.; Nicholson, C.; Zlokovic, B.V.; et al. Clearance Systems in the Brain-Implications for Alzheimer Disease. Nat. Rev. Neurol. 2015, 11, 457-470. [CrossRef]

8. Shibata, M.; Yamada, S.; Kumar, S.R.; Calero, M.; Bading, J.; Frangione, B.; Holtzman, D.M.; Miller, C.A.; Strickland, D.K.; Ghiso, J.; et al. Clearance of Alzheimer's Amyloid-ss (1-40) Peptide from Brain by LDL Receptor-Related Protein-1 at the Blood-Brain Barrier. J. Clin. Investig. 2000, 106, 1489-1499. [CrossRef]

9. Louveau, A.; Smirnov, I.; Keyes, T.J.; Eccles, J.D.; Rouhani, S.J.; Peske, J.D.; Derecki, N.C.; Castle, D.; Mandell, J.W.; Lee, K.S.; et al. Structural and Functional Features of Central Nervous System Lymphatic Vessels. Nature 2015, 523, 337-341. [CrossRef]

10. Peng, W.; Achariyar, T.M.; Li, B.; Liao, Y.; Mestre, H.; Hitomi, E.; Regan, S.; Kasper, T.; Peng, S.; Ding, F.; et al. Suppression of Glymphatic Fluid Transport in a Mouse Model of Alzheimer's Disease. Neurobiol. Dis. 2016, 93, 215-225. [CrossRef] 
11. Harrison, I.F.; Ismail, O.; Machhada, A.; Colgan, N.; Ohene, Y.; Nahavandi, P.; Ahmed, Z.; Fisher, A.; Meftah, S.; Murray, T.K.; et al. Impaired Glymphatic Function and Clearance of Tau in an Alzheimer's Disease Model. Brain 2020, 143, 2576-2593. [CrossRef]

12. Da Mesquita, S.; Louveau, A.; Vaccari, A.; Smirnov, I.; Cornelison, R.C.; Kingsmore, K.; Contarino, C.; Onengut-Gumuscu, S.; Farber, E.; Raper, D.; et al. Functional Aspects of Meningeal Lymphatics in Ageing and Alzheimer's Disease. Nature 2018, 560, 185-191. [CrossRef]

13. Ahn, J.H.; Cho, H.; Kim, J.-H.; Kim, S.H.; Ham, J.-S.; Park, I.; Suh, S.H.; Hong, S.P.; Song, J.-H.; Hong, Y.-K.; et al. Meningeal Lymphatic Vessels at the Skull Base Drain Cerebrospinal Fluid. Nature 2019, 572, 62-66. [CrossRef]

14. Bower, I.N.; Koltowska, K.; Pichol-Thievend, C.; Virshup, I.; Paterson, S.; Lagendijk, A.K.; Wang, W.; Lindsey, B.W.; Bent, S.; Baek, S.; et al. Mural Lymphatic Endothelial Cells Regulate Meningeal Angiogenesis in the Zebrafish. Nat. Neurosci. 2017, 20, 774-783. [CrossRef]

15. Galanternik, M.V.; Castranova, D.; Gore, A.; Blewett, N.H.; Jung, H.M.; Stratman, A.N.; Kirby, M.R.; Iben, J.; Miller, M.F.; Kawakami, K.; et al. A Novel Perivascular Cell Population in the Zebrafish Brain. eLife 2017, 6, e24369. [CrossRef]

16. Van Lessen, M.; Shibata-Germanos, S.; Van Impel, A.; Hawkins, A.T.; Rihel, J.; Schulte-Merker, S. Intracellular Uptake of Macromolecules by Brain Lymphatic Endothelial Cells During Zebrafish Embryonic Development. eLife 2017, 6, e25932. [CrossRef]

17. Shibata-Germanos, S.; Goodman, J.R.; Greig, A.; Trivedi, C.A.; Benson, B.C.; Foti, S.C.; Faro, A.; Castellan, R.; Correra, R.M.; Barber, M.; et al. Structural and Functional Conservation of Non-Lumenized Lymphatic Endothelial Cells in the Mammalian Leptomeninges. Acta Neuropathol. 2019, 139, 383-401. [CrossRef]

18. Padberg, Y.; van Impel, A.; van Lessen, M.; Bussmann, J.; Schulte-Merker, S. Meningeal Lymphatic Endothelial Cells Fulfill Scavenger Endothelial Cell Function and Employ Mrcla for Cargo Uptake. BioRxiv 2019. [CrossRef]

19. Takeda, S.; Hashimoto, T.; Roe, A.D.; Hori, Y.; Spires-Jones, T.L.; Hyman, B.T. Brain Interstitial Oligomeric Amyloid Beta Increases with Age and is Resistant to Clearance from Brain in a Mouse Model of Alzheimer's Disease. FASEB J. 2013, 27, 3239-3248. [CrossRef]

20. Kim, H.Y.; Lee, D.K.; Chung, B.R.; Kim, H.V.; Kim, Y. Intracerebroventricular Injection of Amyloid-beta Peptides in Normal Mice to Acutely Induce Alzheimer-like Cognitive Deficits. J. Vis. Exp. 2016, 109, 53308.

21. Jungbauer, L.M.; Yu, C.; Laxton, K.J.; Ladu, M.J. Preparation of Fluorescently-Labeled Amyloid-Beta Peptide Assemblies: The Effect of Fluorophore Conjugation on Structure and Function. J. Mol. Recognit. 2009, 22, 403-413. [CrossRef]

22. McIntee, F.L.; Giannoni, P.; Blais, S.; Sommer, G.; Neubert, T.A.; Rostagno, A.; Ghiso, J. In vivo Differential Brain Clearance and Catabolism of Monomeric and Oligomeric Alzheimer's Abeta protein. Front. Aging Neurosci. 2016, 8, 223. [CrossRef]

23. Mazaheri, F.; Breus, O.; Durdu, S.; Haas, P.; Wittbrodt, J.; Gilmour, D.; Peri, F. Distinct roles for BAI1 and TIM-4 in the Engulfment of Dying Neurons by Microglia. Nat. Commun. 2014, 5, 4046. [CrossRef]

24. Wang, J.; Gu, B.J.; Masters, C.L.; Wang, Y.J. A Systemic View of Alzheimer Disease-Insights from Amyloid-Beta Metabolism Beyond the Brain. Nat. Rev. Neurol. 2017, 13, 612-623. [CrossRef]

25. Tian, D.-Y.; Cheng, Y.; Zhuang, Z.-Q.; He, C.-Y.; Pan, Q.-G.; Tang, M.-Z.; Hu, X.-L.; Shen, Y.-Y.; Wang, Y.-R.; Chen, S.-H.; et al Physiological Clearance of Amyloid-Beta by the Kidney and its Therapeutic Potential for Alzheimer's Disease. Mol. Psychiatry 2021, 21, 1-9. [CrossRef]

26. Drummond, I.A.; Davidson, A.J. Zebrafish Kidney Development. Methods Cell Biol. 2010, 100, 233-260. [CrossRef]

27. Sehnert, A.J.; Huq, A.; Weinstein, B.M.; Walker, C.; Fishman, M.; Stainier, D.Y.R. Cardiac Troponin T is Essential in Sarcomere Assembly and Cardiac Contractility. Nat. Genet. 2002, 31, 106-110. [CrossRef]

28. Oltrabella, F.; Pietka, G.; Ramirez, I.B.-R.; Mironov, A.; Starborg, T.; Drummond, I.A.; Hinchliffe, K.A.; Lowe, M. The Lowe Syndrome Protein OCRL1 Is Required for Endocytosis in the Zebrafish Pronephric Tubule. PLoS Genet. 2015, 11, e1005058. [CrossRef]

29. Kim, J.D.; Jin, S.W. A Tale of Two Models: Mouse and Zebrafish as Complementary Models for Lymphatic Studies. Mol. Cells 2014, 37, 503-510. [CrossRef]

30. van Impel, A.; Zhao, Z.; Hermkens, D.M.A.; Roukens, M.G.; Fischer, J.C.; Peterson-Maduro, J.; Duckers, H.; Ober, E.A.; Ingham, P.W.; Schulte-Merker, S. Divergence of Zebrafish and Mouse Lymphatic Cell Fate Specification Pathways. Development 2014, 141, 1228-1238. [CrossRef]

31. Zhao, L.N.; Long, H.; Mu, Y.; Chew, L.Y. The Toxicity of Amyloid Beta Oligomers. Int. J. Mol. Sci. 2012, 13, 7303-7327. [CrossRef] [PubMed]

32. Hogan, B.; Bos, F.L.; Bussmann, J.; Witte, M.; Chi, N.C.; Duckers, H.J.; Schulte-Merker, S. ccbe1 is Required for Embryonic Lymphangiogenesis and Venous Sprouting. Nat. Genet. 2009, 41, 396-398. [CrossRef] [PubMed]

33. Volpe, B.A.; Fotino, T.H.; Steiner, A.B. Confocal Microscope-Based Laser Ablation and Regeneration Assay in Zebrafish Interneuromast Cells. J. Vis. Exp. 2020, 15, e60966. [CrossRef] [PubMed]

34. Kim, H.Y.; Kim, H.V.; Jo, S.; Lee, C.J.; Choi, S.Y.; Kim, D.J.; Kim, Y. EPPS Rescues Hippocampus-Dependent Cognitive Deficits In APP/PS1 Mice by Disaggregation of Amyloid-Beta Oligomers and Plaques. Nat. Commun. 2015, 6, 8997. [CrossRef]

35. De Strooper, B.; Karran, E. The Cellular Phase of Alzheimer's Disease. Cell 2016, 164, 603-615. [CrossRef]

36. Yeung, J.H.Y.; Palpagama, T.H.; Tate, W.P.; Peppercorn, K.; Waldvogel, H.J.; Faull, R.L.M.; Kwakowsky, A. The Acute Effects of Amyloid-Beta1-42 on Glutamatergic Receptor and Transporter Expression in the Mouse Hippocampus. Front. Neurosci. 2019, 13, 1427. [CrossRef] 
37. Javed, I.; Peng, G.; Xing, Y.; Yu, T.; Zhao, M.; Kakinen, A.; Faridi, A.; Parish, C.; Ding, F.; Davis, T.P.; et al. Inhibition of Amyloid Beta Toxicity in Zebrafish with a Chaperone-Gold Nanoparticle Dual Strategy. Nat. Commun. 2019, 10, 378. [CrossRef]

38. Bhattarai, P.; Thomas, A.K.; Cosacak, M.I.; Papadimitriou, C.; Mashkaryan, V.; Froc, C.; Reinhardt, S.; Kurth, T.; Dahl, A.; Zhang, Y.; et al. IL4/STAT6 Signaling Activates Neural Stem Cell Proliferation and Neurogenesis upon Amyloid-beta42 Aggregation in Adult Zebrafish Brain. Cell Rep. 2016, 17, 941-948. [CrossRef]

39. Özcan, G.G.; Lim, S.; La Leighton, P.; Allison, W.T.; Rihel, J. Sleep is Bi-Directionally Modified by Amyloid Beta Oligomers. eLife 2020, 9, 3995. [CrossRef]

40. Castranova, D.; Samasa, B.; Galanternik, M.V.; Jung, H.M.; Pham, V.N.; Weinstein, B.M. Live Imaging of Intracranial Lymphatics in the Zebrafish. Circ. Res. 2021, 128, 42-58. [CrossRef]

41. Mato, M.; Ookawara, S.; Aikawa, E.; Kawasaki, K. Studies on Fluorescent Granular Perithelium (F.G.P.) of Rat Cerebral Cortex —Especially Referring to Morphological Changes in Aging. Anat. Anzeiger. 1981, 149, 486-501.

42. Kierdorf, K.; Masuda, T.; Jordão, M.J.C.; Prinz, M. Macrophages at CNS interfaces: Ontogeny and Function in Health and Disease. Nat. Rev. Neurosci. 2019, 20, 547-562. [CrossRef]

43. Weller, R.O.; Subash, M.; Preston, S.D.; Mazanti, I.; Carare, R.O. Perivascular Drainage of Amyloid-Beta Peptides from the Brain and its Failure in Cerebral Amyloid Angiopathy and Alzheimer's Disease. Brain Pathol. 2008, 18, 253-266. [CrossRef]

44. Mato, M.; Ookawara, S. Influences of Age and Vasopressin on the Uptake Capacity of Fluorescent Granular Perithelial Cells (FGP) of Small Cerebral Vessels of the Rat. Am. J. Anat. 1981, 162, 45-53. [CrossRef]

45. Mato, M.; Ookawara, S.; Kurihara, K. Uptake of Exogenous Substances and Marked Infoldings of the Fluorescent Granular Pericyte in Cerebral Fine Vessels. Am. J. Anat. 1980, 157, 329-332. [CrossRef]

46. Hawkes, C.A.; McLaurin, J. Selective Targeting of Perivascular Macrophages for Clearance of Beta-Amyloid in Cerebral Amyloid Angiopathy. Proc. Natl. Acad. Sci. USA 2009, 106, 1261-1266. [CrossRef]

47. Mawuenyega, K.G.; Sigurdson, W.; Ovod, V.; Munsell, L.; Kasten, T.; Morris, J.C.; Yarasheski, K.E.; Bateman, R.J. Decreased Clearance of CNS b-Amyloid in Alzheimer's Disease. Science 2010, 330, 1774. [CrossRef]

48. Verghese, P.B.; Castellano, J.M.; Garai, K.; Wang, Y.; Jiang, H.; Shah, A.; Bu, G.; Frieden, C.; Holtzman, D.M. ApoE Influences Amyloid-Beta (Abeta) Clearance Despite Minimal Apoe/Abeta Association in Physiological Conditions. Proc. Natl. Acad. Sci. USA 2013, 110, E1807-E1816. [CrossRef]

49. Zhao, Z.; Sagare, A.P.; Ma, Q.; Halliday, M.R.; Kong, P.; Kisler, K.; Winkler, E.A.; Ramanathan, A.; Kanekiyo, T.; Bu, G.; et al. Central role for PICALM in Amyloid-Beta Blood-Brain Barrier Transcytosis and Clearance. Nat. Neurosci. 2015, 18, 978-987. [CrossRef]

50. Michaud, J.-P.; Bellavance, M.-A.; Préfontaine, P.; Rivest, S. Real-Time In Vivo Imaging Reveals the Ability of Monocytes to Clear Vascular Amyloid Beta. Cell Rep. 2013, 5, 646-653. [CrossRef]

51. Zagrean, A.-M.; Hermann, D.M.; Opris, I.; Zagrean, L.; Popa-Wagner, A. Multicellular Crosstalk Between Exosomes and the Neurovascular Unit after Cerebral Ischemia. Therapeutic Implications. Front. Neurosci. 2018, 12, 811. [CrossRef]

52. Glabe, C.G. Structural Classification of Toxic Amyloid Oligomers. J. Biol. Chem. 2008, 283, 29639-29643. [CrossRef]

53. Lee, W.; Lee, S.W.; Lee, G.; Yoon, D.S. Atomic Force Microscopy Analysis of EPPS-Driven Degradation and Reformation of Amyloid-beta Aggregates. J. Alzheimers Dis. Rep. 2018, 2, 41-49. [CrossRef]

54. Jung, H.M.; Castranova, D.; Swift, M.R.; Pham, V.N.; Galanternik, M.V.; Isogai, S.; Butler, M.G.; Mulligan, T.S.; Weinstein, B.M. Development of the Larval Lymphatic System in the Zebrafish. Development 2017, 144, 2070-2081. [CrossRef]

55. Kwan, K.M.; Fujimoto, E.; Grabher, C.; Mangum, B.D.; Hardy, M.E.; Campbell, D.; Parant, J.M.; Yost, H.J.; Kanki, J.P.; Chien, C.-B. The Tol2kit: A Multisite Gateway-Based Construction Kit Fortol2 Transposon Transgenesis Constructs. Dev. Dyn. 2007, 236, 3088-3099. [CrossRef] 